\title{
The Role of Workfare in Striking a Balance between Incentives and Insurance in the Labour Market
}

\author{
TORBEN M. ANDERSEN \\ MICHAEL SVARER
}

CESIFo Working PAPER No. 2267

CATEGORY 4: LABOUR MARKETS

APRIL 2008

Presented at CESifo Area CONFEREnCE on “EMPloyment ANd Social Protection”, May 2007

SUPPORT BY THE WGL LEIBNIZ ASSOCIATION WITHIN THE PROJECT “HOW TO CONSTRUCT EUROPE”

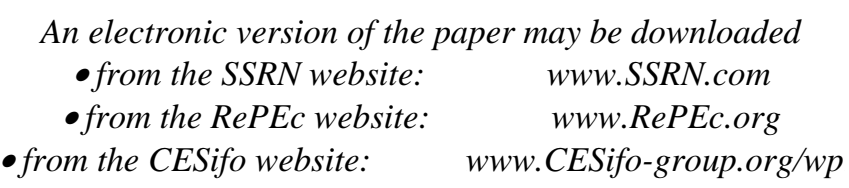




\title{
The Role of Workfare in Striking a Balance between Incentives and Insurance in the Labour Market
}

\begin{abstract}
Workfare policies are often introduced in labour market policies to improve the trade-off between incentives and insurance as an alternative to benefit reductions. Most of the debate on such policies has focussed on the direct effect of those participating in the scheme, and in particular the possible locking-in effect reducing job search. In a general equilibrium search framework, we show that the effects of workfare policies critically depend on the response of those not in the programme when they take into account that workfare is a condition for remaining eligible for unemployment benefits. This implies that unemployed not yet in workfare may search more for regular jobs, and employed may accept lower wages since the outside option becomes less attractive. Introduction of workfare policies into an unemployment insurance scheme is shown to contribute to a reduction in both open and total unemployment. It is also shown that the direct search effects of workfare policies are a poor indicator of the overall effect workfare policies have on labour market policies.
\end{abstract}

JEL Code: J68.

Keywords: active labour market policy, risk, search, unemployment.

Torben M. Andersen

School of Economics and Management

University of Aarhus

Building 322

8000 Aarhus C

Denmark

tandersen@econ.au.dk
Michael Svarer

School of Economics and Management

University of Aarhus

Building 1326

8000 Aarhus $C$

Denmark

msvarer@econ.au.dk

March 2008

Comments from Michael Rosholm and Martin Werding as well as participants at the CESifo area conference on Employment and Social Protection and at seminars in Kiel and EPRN are gratefully acknowledged. This paper is part of the CESifo project on "How to Construct Europe". 


\section{Introduction}

A key policy challenge is to ensure a proper balance between incentives and insurance in the labour market. The incentive part is related to active job search including reallocation across jobs, skills and geographical dimensions to make the labour market flexible and able to cope with shocks and structural changes, ensuring a low and stable unemployment rate. The insurance part is related to the risk associated with loss of jobs and incomes carried by individuals. The challenge is to ensure both incentives and insurance so as to combine economy wide demands to the labour market with individual desires for security.

The issue of how to strike a balance between incentives and insurance in the labour market has recently been much discussed under the heading of flexicurity, which alludes to the possibility of having flexible rules for hiring and firing of workers in combination with a generous unemployment insurance scheme coping with individual risks associated with labour market flexibility. Denmark is often portrayed as a model example of a flexicurity system with very flexible firing rules and a generous unemployment insurance system. Since the unemployment rate in Denmark is relatively low, this has been taken to illustrate the possibility of striking a balance between incentives and insurance. However, in accounting for the Danish experience, it is important also to take into account the role of active labour market policies in the form of workfare elements. Both the rather flexible dismissal rules and the unemployment insurance (and social assistance) system have been virtually unchanged for many years, and were also in place during the period from the mid 1970 s to the early 1990s with double digit unemployment rates. The major changes in Denmark in recent years are a sequence of reforms ${ }^{1}$ during the 1990s and continued in recent years which has strengthened the third pillar of Danish labour market policy, namely the active labour market policy where workfare elements have come to play an important role (for details see e.g. Andersen and Svarer (2007)).

The role of workfare in striking a balance between incentives and insurance is thus an important policy issue. The emphasis on active labour market policies is, however,

\footnotetext{
${ }^{1}$ The main orientation of the reform is a shift from a passive orientation of the system focusing on income maintenance to an active focus on ensuring employment. Important policy changes include i) a strengthening of workfare elements in both the unemployment benefit and social assistance scheme, ii) eliminating participation in activation measures as a possibility to renew eligibility for unemployment benefits, iii) shortening of the effective duration of benefits. In short, this can be interpreted as strengthening the incentive side while maintaining a reasonable level of insurance (without reducing benefits), see Andersen and Svarer (2007).
} 
not a new phenomenon, and various elements can be found in the labour market policies implemented in many countries. The experience with active labour market policies is rather mixed. A large number of empirical analyses of various elements of active labour market policies exists, but they leave a rather unclear message. In a recent survey, Kluve (2006) concludes that there are some positive effects of private job creation programmes and measures aiming at enhancing job search efficiency, whereas training programmes and public sector employment are less efficient instruments which may even have a negative effect on employment. However, most of these analyses are partial in nature, focussing on the direct effects of various policy measures neither taking into account the general equilibrium effects (wage responses, search incentives for other groups, employment creation etc.) nor the financing of active labour market policies. However, partial equilibrium reasoning may provide a distorted picture of the overall effects of given policies. There is thus a need to clarify in a general equilibrium setting which elements of active labour market policies that can be used to mitigate the trade-off between insurance and incentives.

Most analyses of workfare focus on the direct effect of the programme; that is, the potential of the programme to improve qualifications, and thus re-employment possibilities, and the locking-in effect arising from programme participation tending to reduce job search $^{2}$. However, in a labour market with flows in and out of unemployment, the introduction of workfare programmes will affect not only those participating but also others anticipating that they may eventually if unemployed end up in a workfare programme. Thus, both unemployed (not in activation) and employed are affected. The search effort of the unemployed may increase to reduce the risk of ending up in workfare (being less attractive than passively receiving benefits). It follows that that overall job search is affected by two counteracting effects, namely the negative locking-in effect for those in workfare and the positive threat or motivation effect for the unemployed. Moreover, and less obvious, even the direct effect of workfare on total search effort is not pivotal since there is also a wage effect. This wage effect arises because workfare affects the outside option of employed workers; that is, the outside option deteriorates, and this tends to lead to wage moderation. Wage moderation boosts job creation, which, in turn, will contribute to increase employment (matching) in the labour market. Therefore, the direct effect of workfare policies on programme participants may be a poor indicator of how such

\footnotetext{
${ }^{2}$ Subsequent job search may also be affected. It is possible that participants will search more actively since they will perceive the chances of finding a job to have improved. Oppositely, the types of jobs searched may be narrowed to the extent that the individual tries to match jobs to specific training.
} 
policies affect labour market performance. This paper aims at clarifying the joint effect of workfare policies on search and job creation, and thus overall labour market performance.

The contribution of this paper is to consider how workfare as an element of an unemployment benefit scheme can be an instrument in striking a balance between considerations for incentives and insurance. Specifically, we analyse whether introduction of workfare policies can improve labour market performance for given benefits. We present a general equilibrium analysis of workfare in a basic search framework ${ }^{3}$. A tax financed unemployment insurance scheme deals with the insurance aspect, but may for well-known reasons create incentive problems inducing insufficient job search on the part of the unemployed. To focus on the search and job creation effects, we disregard human capital considerations; that is, human capital is assumed not to depreciate over the unemployment spell (see Pavoni and Violanti (2007)), and workfare programmes do not affect human capital (reemployment probabilities are the same for unemployed and programme participants).

Notice also that workfare policies have two dimensions, namely the transition rate from unemployment to activation and the work requirement. The two are not in general equivalent, and therefore the composition of workfare policies are of importance for search effort and wage determination, and thus unemployment. It is an implication that changes in benefits and workfare policies are not equivalent even from a utility perspective in a search environment, and therefore this policy tool may critically affect the incentive and insurance trade-off.

We consider these mechanisms both analytically and in numerical simulations. The key issue addressed is the effects of workfare requirements on search effort undertaken by different groups in the labour market, and their effects on total search effort and wage determination and therefore on the overall unemployment rate (open and total). We consider the distributional consequences in terms of the fraction of workers in different states (employment, benefits, and workfare) and their income and utility levels.

This paper contributes to the theoretical literature on workfare policies. Besley and Coate $(1992,1995)$ pointed out that workfare can be used as a screening device and therefore allows a better targeting of income transfers. This effect of workfare policies has been further analysed by e.g. Chambers (1989) and Betts (1998). In a labour market context, Kreiner and Tranæs (2005) analyse workfare as a screening device affecting the optimal unemployment insurance offered for a given unemployment risk. Frederiksson and Holmlund (2006) compare workfare policies with time limits and sanctions in an unemployment

\footnotetext{
${ }^{3}$ See Kolm and Tonin (2007) for an analysis of the effects of in-work benefits in a similar framework.
} 
insurance scheme and argue that workfare does not improve search incentives but may hamper them by being time consuming (the locking-in effect). Hence, they argue that workfare is dominated by time limits and monitoring of search. However, Holzner, Meier and Werding (2006) find in an efficiency wage model that workfare may lessen the nonshirking condition since unemployment benefits become less attractive, and this, in turn, shifts the wage curve.

An important question from a normative perspective is whether there is any rationale for introducing workfare policies or whether these policies are dominated by other policy measures like benefit cuts. In the literature on income redistribution programmes, it is a general finding that workfare as such does not leave more leverage in balancing incentives and redistribution (insurance) since a change in benefits or work requirements would work via changing the utility offered to people receiving transfers. Therefore, under a standard utility metric, workfare does not play a large role as part of optimal policies ${ }^{45}$. The situation changes if the policy objective is cast in terms of income or consumption possibilities (income maintenance) rather than utility since workfare in this case can be used to strengthen incentives for given benefit or income levels, see Besley and Coate $(1992,1995)$. It is reasonable to argue that distributional discussions usually focus on income, and therefore workfare may create an extra degree of freedom in redistribution policies. Moreover, income is interpersonally comparable, which utility is not. An alternative justification may be given in terms of desert-sensitive altruism (for a definition see e.g. Luttens and Valfort (2007)) implying that "hard working" individuals will oppose contributing to redistribution towards the "lazy"; i.e. the political support for generous unemployment schemes may be higher if it is associated with workfare elements. This is also related to work norms often permeating policy discussions. In any case, the primary objective of the present paper is to present a positive analysis of how workfare policies affect labour market performance, in particular open and total unemployment.

The paper is organized as follows: Section 2 sets up the basic model and considers the three effects of workfare, i.e. the locking-in effect, the threat effect, and the wage effect. The overall effects of the two dimensions of workfare (intensity and work requirement) are worked out in section 3 , and section 4 provides a numerical illustration of how workfare

\footnotetext{
${ }^{4}$ It has been shown that this equivalence result need not hold if workfare activities are productive (Chambers (1989) and Betts (1998)).

${ }^{5}$ Kreiner and Tranæs (2005) show in an unemployment insurance context with an adverse selection problem that it is Pareto-improving to introduce workfare.
} 
policies affect labour market performance. Finally, section 5 offers a few concluding remarks and discusses the empirical evidence on the mechanisms analysed in the paper as well as possible extensions of the framework.

\section{A search model with workfare}

This section develops a very stylized search model ${ }^{6}$ to bring forth some basic effects of workfare as an instrument in labour market policies. Agents are homogeneous but differ in their labour market status, and frictions are associated with transition between labour market states.

\section{$2.1 \quad$ Workers}

Consider a labour market regime in which unemployed are entitled to a benefit $b$ when unemployed. Unemployed persons may be required to participate in activation programmes to remain eligible for the benefit. The activation requirement may either be imposed after having claimed unemployment benefits for a certain period of time or at the discretion of the labour market authorities. As argued by Frederiksson and Holmlund (2006), a fixed time duration can be approximated by a system in which there is a stochastic transition from passive benefits to workfare. A scheme where the activation (duration and type of activity) is decided at the discretion of the authorities would thus, seen from an individual perspective, be a stochastic workfare scheme. The probability that an unemployed is required to participate in activation ${ }^{7}$ with a work requirement $l_{a}$ is denoted $p_{a u}\left(0 \leq p_{a u} \leq 1\right)$. These two dimensions of workfare $\left(l_{a}, p_{a u}\right)$ are exogenous policy instruments.

Agents search for jobs with intensity $s_{u}$ when unemployed, and $s_{a}$ when in activation. The wage rate is denoted $w$, the tax rate $\tau$, and the work requirement $l_{e}$ (exogenous). Unemployed are entitled (possible contingent on participation in a workfare programme) to a benefit $b$. The instantaneous utility depends on consumption (= disposable income) and leisure $\left(F_{i}=1-l_{i}-s_{i}\right.$, where the time endowment has been normalized to unity, $l$ denotes time worked, and $s$ time spent searching for jobs), i.e.

\footnotetext{
${ }^{6}$ The model structure is closely related to Frederiksson and Holmlund (2006).

${ }^{7}$ As modelled, here transition from activation is only to employment. One could think of transition to either ordinary unemployment benefits or social assistance (lower compensation level). Adding these features would not change anything qualitatively.
} 


$$
\begin{array}{ccc}
h\left(w[1-\tau], 1-l_{e}\right) & \text { if } & \text { employed } \\
g\left(b, 1-s_{u}\right) & \text { if } & \text { receiving unemployment benefits } \\
g\left(b, 1-s_{a}-l_{a}\right) & \text { if } & \text { in activation programme }
\end{array}
$$

where both $h$ and $g$ are increasing and concave functions in their arguments. We allow the utility functions to differ between employed and unemployed workers to capture eventual stigmatization effects of being without a regular job ${ }^{8}$.

Assuming a constant interest rate $\rho$, it follows that the value functions (in Steady State) associated with the three labour market states are

$$
\begin{aligned}
\rho V^{E} & =h\left(w[1-\tau], 1-l_{e}\right)+p_{u e}\left[V^{U}-V^{E}\right] \\
\rho V^{U} & =g\left(b, 1-s_{u}\right)+\alpha s_{u}\left[V^{E}-V^{U}\right]+p_{a u}\left[V^{A}-V^{U}\right] \\
\rho V^{A} & =g\left(b, 1-s_{a}-l_{a}\right)+\alpha s_{a}\left[V^{E}-V^{A}\right]
\end{aligned}
$$

where job offers arrive with probability $\alpha s_{u}$ for unemployed, and $\alpha s_{a}$ for workers in activation programmes. $\alpha$ is the job arrival rate conditional on search, and it is endogenous, see below. Note that the employment probabilities are the same for the two groups, provided they exert the same search effort. Hence, there are no human capital differences between the two groups nor any change in human capital from participating in activation ${ }^{9}$. There is an exogenous job separation rate $p_{u e}\left(0<p_{u e}<1\right)$.

From (1), (2) and (3), we have that the value functions for the three labour market states can be written as

$$
\begin{aligned}
{\left[\rho+p_{u e}\right] V^{E} } & =h\left(w[1-\tau], 1-l_{e}\right)+p_{u e} V^{U} \\
{\left[\rho+\alpha s_{u}+p_{a u}\right] V^{U} } & =g\left(b, 1-s_{u}\right)+\alpha s_{u} V^{E}+p_{a u} V^{A} \\
{\left[\rho+\alpha s_{a}\right] V^{A} } & =g\left(b, 1-s_{a}-l_{a}\right)+\alpha s_{a} V^{E}
\end{aligned}
$$

To see the role of activation, it is useful to note that the pay-off as unemployed can be written

$$
V^{U}=\frac{\rho+\alpha s_{u}}{\rho+\alpha s_{u}+p_{a u}} \widehat{V}^{U}+\frac{p_{a u}}{\rho+\alpha s_{u}+p_{a u}} V^{A}<\widehat{V}^{U}
$$

\footnotetext{
${ }^{8}$ None of the analytical results depend on this assumption.

${ }^{9}$ These human capital effects may be either positive via forms of training or maintenance of human and social capital, or negative in terms of duration dependent depreciation of these.
} 
where $\widehat{V}^{U}$ is the pay-off to unemployed in the absence of activation $\left(p_{a u}=0\right)$ given as

$$
\widehat{V}^{U}=\frac{g\left(b, 1-s_{u}\right)+\alpha s_{u} V^{E}}{\left(\rho+\alpha s_{u}\right)}
$$

The pay-off as unemployed (4) is thus a convex combination of the pay-offs in the absence of activation and under activation. Hence, workfare can be interpreted as a randomized sanction in the unemployment insurance scheme in the sense that with probability $p_{a u}$ the individual is required to participate in activation to remain eligible for benefits.

The participation constraint is that employed are always better off than the unemployed

$$
V^{E}-V^{U}>0
$$

and that the pay-off for those in activation is non-negative

$$
V^{A} \geq 0
$$

Note that it is implied that the unemployed are always better off than individuals in activation programmes

$$
V^{U}-V^{A}>0 \quad \text { for } \quad p_{a u}>0, \quad l_{a}>0
$$

It is obvious that activation requirements $\left(l_{a}>0\right)$ worsen the situation for those in activation. However, and this is crucial, it also affects the position as unemployed since there is possible transition into activation (the threat effect), cf. (5) below. A change in the transition rate from unemployment into activation does not directly affect those in activation, but it has an effect on the unemployed in terms of increasing the likelihood of changing status from being unemployed to being in activation, cf. (5).

$$
\begin{array}{cc}
\frac{\partial V^{A}}{\partial l_{a}}=-g_{F}^{\prime}\left(b, 1-s_{a}-l_{a}\right)<0 & \frac{\partial V^{A}}{\partial p_{a u}}=0 \\
\frac{\partial V^{U}}{\partial l_{a}}=\frac{p_{a u}}{\rho+\alpha s_{u}+p_{a u}} \frac{\partial V^{A}}{\partial l_{a}}<0 & \frac{\partial V^{U}}{\partial p_{a u}}=\frac{\rho+\alpha s_{u}}{\left[\rho+\alpha s_{u}+p_{a u}\right]^{2}}\left[V^{A}-\widehat{V}^{U}\right]<0
\end{array}
$$

A key question for policy design is whether workfare elements can release any incentive effects different from a benefit reduction, cf. the introduction. Although there, from a utility perspective, is equivalence between benefit reductions and workfare elements, the effects will differ across the three groups in the labour market: employed, unemployed and activated. This is so for two reasons. First, although a reduction in benefits would affect unemployed and activated in similar ways, this is not the case for workfare policies. The reason is that workfare has no direct effect on the instantaneous utility for the unemployed 
$\left(g\left(b, 1-s_{u}\right)\right)$ but a prospective effect via the risk of ending up in activation (the threat or motivation effect). Hence, changes in workfare demands $\left(l_{a}\right)$ and benefits $(b)$ would not have similar effects for the two groups, see below. Secondly, benefit changes and workfare requirements affect search incentives differently. The reason is that workfare requirement affects the marginal cost of search directly, whereas benefits have an effect via an income effect (see below).

The above suggests that the incentive effects of changing the incidence of workfare $\left(p_{a u}\right)$ and the activity requirement $\left(l_{a}\right)$ differ between the unemployed and those in activation programmes. To see the difference, consider the marginal rate of substitution of the two instruments for given pay-off gains $\left(V^{E}-V^{U}\right.$ and $\left.V^{E}-V^{A}\right)$ and search effort $\left(s_{u}\right.$ and $s_{a}$ ). As shown in the appendix $B$, we have that

$$
\begin{aligned}
\left.\frac{d p_{a u}}{d l_{a}}\right|_{U} & =-\frac{p_{a u}}{\rho+\alpha s_{a}} \frac{g_{F}^{\prime}\left(b, 1-s_{a}-l_{a}\right)}{V^{U}-V^{A}}<0 \\
\left.\frac{d p_{a u}}{d l_{a}}\right|_{A} & =\frac{\rho+p_{u e}+p_{a u}+\alpha s_{u}}{p_{u e}} \frac{g_{F}^{\prime}\left(b, 1-s_{a}-l_{a}\right)}{V^{U}-V^{A}}>0
\end{aligned}
$$

which gives the marginal rate of substitution between the transition rate and the workfare requirement for the unemployed and those on workfare, respectively. The intuition for the negative rate of substitution for unemployed is straightforward; increasing the work requirement makes the state of unemployment less attractive due to the possibility of being transferred to activation, and this can be compensated by a lower incidence of activation. Therefore, for the unemployed, the two instruments are substitutes. For those in activation, the situation is different. A higher work requirement would affect utility negatively, and for the utility differences to be unchanged the state of employment has to be less attractive which is the case (due to the risk of job loss) if unemployment is more likely to lead to activation, i.e. $p_{a u}$ is higher. Hence, for those on workfare, the two instruments are complements. It is also seen that for both types, the marginal rate of substitution depends both on the incidence of workfare $\left(p_{a u}\right)$ and the work requirement $\left(l_{a}\right)$, suggesting that there may be non-linearities in the effects of the two dimensions. 


\subsection{Search effort}

Individuals choose search effort taking all macro variables $(w, \tau, \alpha)$ as given, and hence the search effort is determined by ${ }^{10}$

$$
\begin{aligned}
g_{F}^{\prime}\left(b, 1-s_{u}\right) & =\alpha\left[V^{E}-V^{U}\right] \\
g_{F}^{\prime}\left(b, 1-s_{a}-l_{a}\right) & =\alpha\left[V^{E}-V^{A}\right]
\end{aligned}
$$

The LHS gives the marginal costs of search and the RHS the marginal gain as the product of the job finding probability $\alpha$ and the utility gain from shifting from the current state into employment.

Since $V^{U}-V^{A}>0$, it follows that

$$
g_{F}^{\prime}\left(b, 1-s_{a}-l_{a}\right)>g_{F}^{\prime}\left(b, 1-s_{u}\right)
$$

and therefore

$$
s_{u}<s_{a}+l_{a}
$$

i.e. those in activation spend more time in total (activation plus search) than the unemployed (search only), but it is in general ambiguous whether search activity is highest for the unemployed or those in activation $\left(s_{a} \lesseqgtr s_{u}\right)$.

An important question is whether workers in activation would search less than other unemployed workers. This is the so-called locking-in effect. It follows from (7) that no unambiguous statements can be made due to two counteracting effects. First, activation is time consuming, and this tends to increase the marginal costs of search and therefore to lower search effort. Second, activation requirements make activation less attractive than unemployment $\left(V^{U}-V^{A}>0\right)$, and therefore workers in activation have more to gain by becoming employed, which tends to make them search more. Hence, in general it is ambiguous whether there is a locking-in effect. Unemployed and those in activation also react differently to changes in the work requirement (see Appendix $C$ for proof of signs)

$$
\begin{aligned}
\frac{\partial s_{u}}{\partial l_{a}} & =\frac{-1}{v_{F}^{\prime \prime}\left(b, 1-s_{u}\right)} \frac{\partial \alpha\left[V^{E}-V^{U}\right]}{\partial l_{a}}>0 \\
\frac{\partial s_{a}}{\partial l_{a}} & =\frac{-1}{v_{F}^{\prime \prime}\left(1-s_{a}+l_{a}\right)} \frac{\partial \alpha\left[V^{E}-V^{A}\right]}{\partial l_{a}}-1 \lesseqgtr 0
\end{aligned}
$$

\footnotetext{
${ }^{10}$ The second order conditions are fulfilled given the concavity of the $g$-function.
} 
Strengthening the work requirement induces the unemployed to exert more search effort since it increases the marginal gain from becoming employed $\left(\frac{\partial \alpha\left[V^{E}-V^{U}\right]}{\partial l_{a}}>0\right)$. A similar effect is present for those in activation, but it is counteracted by the extra time spent in activation. Hence, it is possible that strengthened activation requirements may increase the search effort of unemployed - a threat effect - while decreasing the search effort of those in activation - a locking-in effect. The overall effect on search is therefore ambiguous.

For the incidence or risk of being on workfare $\left(p_{u e}\right)$, we also find a difference in how it affects the unemployed and those in activation since we have (for proof of signs see appendix $C$ )

$$
\begin{aligned}
\frac{\partial s_{u}}{\partial p_{a u}} & =\frac{-1}{v_{F}^{\prime \prime}\left(b, 1-s_{u}\right)} \frac{\partial \alpha\left[V^{E}-V^{U}\right]}{\partial p_{a u}}>0 \\
\frac{\partial s_{a}}{\partial p_{a u}} & =\frac{-1}{v_{F}^{\prime \prime}\left(b, 1-s_{a}+l_{a}\right)} \frac{\partial \alpha\left[V^{E}-V^{A}\right]}{\partial p_{a u}}<0
\end{aligned}
$$

i.e. a large risk of transiting into activation induces the unemployed to search more for jobs because the alternative is now less attractive. Oppositely, the search effort of those already in activation decreases since getting a job becomes less attractive (due to the risk of losing it again and ending up in activation).

\subsection{Matching}

Hiring and transitions into employment are determined via a matching mechanism given as

$$
m(s, v)
$$

where $s$ denotes effective search and $v$ the vacant jobs (see below) ${ }^{11}$. The matching function is assumed to be increasing in both arguments and to display constant returns. Effective or total search is determined by

$$
s=s_{u} u+s_{a} a
$$

where $u$ is the fraction of the population being on unemployment benefits, and $a$ is accordingly the fraction in activation. The job finding rate is

$$
\alpha=\frac{m(s, v)}{s}=m(1, \theta)
$$

\footnotetext{
${ }^{11}$ Expressed in per capita terms, i.e the population is $N=E+U+A$, and $e=E / N, u=U / N$, and $a=A / N$.
} 
where $\theta=\frac{v}{s}$, and hence $\alpha(\theta), \alpha^{\prime}(\theta)>0$. Firms fill vacancies at the rate $q=\frac{m(s, v)}{v}=$ $m\left(\theta^{-1}, 1\right), q^{\prime}(\theta)<0$.

Inflow and outflow into jobs balance in equilibrium, i.e.

$$
[1-u-a] p_{u e}=\alpha\left[s_{u} u+s_{a} a\right]
$$

as they also do for activation, i.e.

$$
\alpha s_{a} a=p_{a u} u
$$

\subsection{Firms and vacancies}

An employed worker produces an output $y$, while the cost of having an unfilled vacancy is $k y(k>0)$. The value functions are

$$
\begin{aligned}
& \rho J^{V}=-k y+q\left(J^{E}-J^{V}\right) \\
& \rho J^{E}=y-w+p_{u e}\left(J^{V}-J^{E}\right)
\end{aligned}
$$

Vacancies are created up to the point where (free entry) $J^{V}=0$, implying the following relationship between the wage rate $(w)$ and labour market tightness $(\theta)$

$$
w=\left[1-\left(\rho+p_{u e}\right) \frac{k}{q(\theta)}\right] y
$$

This gives a relation implying that the higher the wage rate $(w)$, the higher the rate at which firms are filling jobs $(q(\theta))$; i.e. a high wage is associated with a low $\theta$ and thus less job creation (fewer vacancies relative to total search effort). Note for later reference that this implies that the job finding rate $\alpha$ is decreasing in the wage rate. The value of a filled job is

$$
J^{E}=\frac{k y}{q}
$$

\subsection{Wage determination}

The wage rate is assumed to be set in a Nash-bargain between workers and the firm, i.e.

$$
w=\arg \max \left[V^{E}-V^{U}\right]^{\beta}\left[J^{E}-J^{V}\right]^{1-\beta}
$$

where $\beta$ is the (exogenous) bargaining power and $V^{U}$ is taken as given. The first order condition reads

$$
\beta \frac{\frac{\partial V^{E}}{\partial w}}{V^{E}-V^{U}}+(1-\beta) \frac{\frac{\partial J^{E}}{\partial w}}{J^{E}}=0
$$


where it has been used that $J^{V}=0$. The first order condition can be written

$$
\Psi\left(w, \tau, V^{E}-V^{U}, q\right) \equiv \beta \frac{h_{w}\left(w[1-\tau], 1-l_{e}\right)}{V^{E}-V^{U}}+(1-\beta) \frac{-1}{J^{E}}=0
$$

and the second-order condition is

$$
\frac{\partial \Psi\left(w, \tau, V^{E}-V^{U}, q\right)}{\partial w}<0
$$

Workfare releases a wage effect. To see this note that

$$
\begin{aligned}
& \frac{\partial \Psi\left(w, \tau, V^{E}-V^{U}, q\right)}{\partial p_{a u}}=-\beta \frac{h_{w}\left(w[1-\tau], 1-l_{e}\right)}{\left[V^{E}-V^{U}\right]^{2}} \frac{\partial\left(V^{E}-V^{U}\right)}{\partial p_{a u}}<0 \\
& \frac{\partial \Psi\left(w, \tau, V^{E}-V^{U}, q\right)}{\partial l_{a}} \equiv-\beta \frac{h_{w}\left(w[1-\tau], 1-l_{e}\right)}{\left[V^{E}-V^{U}\right]^{2}} \frac{\partial\left(V^{E}-V^{U}\right)}{\partial l_{a}}<0
\end{aligned}
$$

Using this and the second-order condition, it follows that

$$
\frac{\partial w}{\partial p_{a u}}<0, \frac{\partial w}{\partial l_{a}}<0
$$

i.e. an increase in both the intensity and work requirement of workfare tends to lower the wage rate. In other words, both of these changes worsen the outside option of the employed in wage negotiations and therefore tend to reduce the wage rate. A lower wage tends to make firms create more vacancies, which, in turn, improves matches etc. The wage effect of workfare may thus be important on par with the direct search effect.

\subsection{Public sector}

The policy instruments of the government are the benefit level $(b)$, the incidence of workfare $\left(p_{a u}\right)$, the work requirement $\left(l_{a}\right)$ and the tax rate $\tau$. The budget constraint for the public sector is

$$
\tau w(1-u-a)=b u+(b+c) a+r
$$

where $c$ is the cost of activation programmes ${ }^{12}$, and $r$ other expenditure requirements of the government. We take the tax rate to be given, and therefore the expenditure level $r$ is endogenous. ${ }^{13}$

It is shown in Appendix $D$ that the model has a well-defined equilibrium, and conditions ensuring a unique equilibrium are given ${ }^{14}$

\footnotetext{
${ }^{12}$ To the extent that activation programmes result in some output, $c$ could be interpreted as the net costs.

${ }^{13}$ This assumption is made in the theoretical analysis to eliminate a non-linearity which would arise if $r$ is taken to be exogenous and $\tau$ endogenous.

${ }^{14}$ Multiple equilibria cannot be ruled out due to the non-linearities in the model. Potentially, there
} 


\section{Workfare policies and labour market policies}

Our main interest is to explore how workfare policies can affect labour market performance, in particular open $(u)$ and total $(u+a)$ unemployment. The effects of the two dimensions of workfare $\left(z=l_{a}, p_{a u}\right)$ on unemployment $(u)$, activation $(a)$ and total unemployment $(u+a)$ are given as (see Appendix $E$ )

$$
\begin{aligned}
\frac{\partial u}{\partial z} & =\frac{-\frac{p_{u e}+\alpha s_{a}}{\alpha s_{a}} u \frac{\partial p_{a u}}{\partial z}-u \frac{\partial \alpha s_{u}}{\partial z}+a \frac{p_{u e}}{\alpha s_{a}} \frac{\partial \alpha s_{a}}{\partial z}}{\left(p_{u e}+\alpha s_{u}\right)+\frac{p_{u e}+\alpha s_{a}}{\alpha s_{a}} p_{a u}} \\
\frac{\partial a}{\partial z} & =\frac{1}{\alpha s_{a}}\left[\frac{\left(p_{u e}+\alpha s_{u}\right) u \frac{\partial p_{a u}}{\partial z}-u p_{a u} \frac{\partial \alpha s_{u}}{\partial z}-\left[p_{u e}+\alpha s_{u}+p_{a u}\right] a \frac{\partial \alpha s_{a}}{\partial z}}{\left(p_{u e}+\alpha s_{u}\right)+\frac{p_{u e}+\alpha s_{a}}{\alpha s_{a}} p_{a u}}\right] \\
\frac{\partial(u+a)}{\partial z} & =\frac{\left[\frac{\alpha\left(s_{u}-s_{a}\right)}{\alpha s_{a}}\right] u \frac{\partial p_{a u}}{\partial z}-\left[1+\frac{p_{a u}}{\alpha s_{a}}\right] u \frac{\partial \alpha s_{u}}{\partial z}-\left[\frac{\alpha s_{u}+p_{a u}}{\alpha s_{a}}\right] a \frac{\partial \alpha s_{a}}{\partial z}}{\left(p_{u e}+\alpha s_{u}\right)+\frac{p_{u e}+\alpha s_{a}}{\alpha s_{a}} p_{a u}}
\end{aligned}
$$

This expression allows us to decompose the changes in the three measures of labour market performance in terms of the effects arising from changes in the transition rate into activation $\left(\frac{\partial p_{a u}}{\partial z}\right)$, and the effective search while unemployed $\left(\frac{\partial \alpha s_{u}}{\partial z}\right)$ and in activation $\left(\frac{\partial \alpha_{a}}{\partial z}\right)$. Considering first the effect released if the incidence of workfare is affected $\left(\frac{\partial p_{a u}}{\partial z}\right)$ (the first term on the RHS of the expressions above). If $\frac{\partial p_{a u}}{\partial z}>0$, the transition from passive to active benefits is increased, which tends to lower open unemployment $\left(\frac{\partial u}{\partial z}<0\right)$, but it increases activation $\left(\frac{\partial a}{\partial z}>0\right)$, and hence the net-effect on total unemployment is ambiguous $\left(\frac{\partial(u+a)}{\partial z} \lesseqgtr 0\right)$. If the change increases the effective job search rate for the unemployment $\frac{\partial \alpha s_{u}}{\partial z}>0$, this contributes to lower unemployment $\left(\frac{\partial u}{\partial z}<0\right)$ and activation $\left(\frac{\partial a}{\partial z}<0\right)$ since fewer will be transferred to activation, and this effect thus unambiguously works to lower total unemployment $\left(\frac{\partial(u+a)}{\partial z}<0\right)$. If the effective job-finding rate for those in activation increases $\frac{\partial \alpha s_{a}}{\partial z}>0$, it will tend to increase open unemployment (total employment goes up and there will be more job separations) $\left(\frac{\partial u}{\partial z}>0\right)$, but activation falls $\left(\frac{\partial a}{\partial z}<0\right)$, and this effect dominates such that total unemployment decreases $\left(\frac{\partial(u+a)}{\partial z}<0\right)$. The above suggests that the effects of workfare policies on labour market performance may be non-monotone.

The findings reported here indicate both that the effects of workfare policies on open unemployment, activation and total unemployment are complicated and that the net-

could be multiple equilibria in the sense of having e.g. an equilibrium with a low tax, low unemployment and high search effort, or an equilibrium with a high tax, high unemployment and low search effort. Since multiplicity of equilibria is not essential for our analysis, we rule it out. 
effect depends on the balance between counteracting effects. Moreover, it brings out that the effective job finding rates are the key transmission mechanisms. We have that it can be decomposed into a wage and a search effect since

$$
\frac{\partial \alpha(w) s_{i}}{\partial z}=\frac{\partial \alpha(w)}{\partial w} \frac{\partial w}{\partial z} s_{i}+\alpha(w) \frac{\partial s_{i}}{\partial z} \quad \text { for } i=u, a, z=p_{a u}, l_{a}
$$

Hence, we have that the wage effect $\left(\frac{\partial \alpha}{\partial w} \frac{\partial w}{\partial z}>0\right.$ since $\frac{\partial \alpha}{\partial w}<0$ and $\frac{\partial w}{\partial z}<0$, cf. Appendix D) unambiguously increases the effective job finding rate for both unemployed and activated, whereas the direct search effect as shown above is more complicated and depends on the dimensions of workfare considered. The work requirement increases search for unemployed but has an ambiguous effect for the activated (see (8) and (9)), while increasing the propensity of activation leads to more search for the unemployed and less for the activated (see (10) and (11)). This also brings out why a focus on the direct search effect of workfare policies may miss an important element of why workfare policies affect labour market performance, namely the wage effect.

The many counteracting search effects of a marginal change in either of the two dimensions of workfare policies blur the fact that introduction of workfare elements in an unemployment insurance scheme may contribute to lower both open and total unemployment. That is, if the unemployment insurance scheme does not have workfare elements, there is an argument for introducing them if the aim is to lower unemployment under a distributional constraint of given benefits. To see this, we neutralize the unambiguous wage effect (assuming a constant wage) and consider search effects only. It can be shown (see Appendix $E$ ) that increasing the incidence of workfare $\left(p_{a u}\right)$ leads to a fall in unemployment, i.e. $\left.\frac{\partial u}{\partial p_{a u}}\right|_{p_{a u}=0}<0$, and lowers total unemployment $\left.\frac{\partial(u+a)}{\partial p_{a u}}\right|_{p_{a u}=0}<0$ provided that the workfare requirement is not too large, i.e. $l_{a}<\bar{l}_{a}$. Similarly, increasing the activity requirement from an initial level of zero leads to a decrease in unemployment $\left(\left.\frac{\partial u}{\partial l_{a}}\right|_{l_{a}=0}<0\right)$ and an increase in the number of unemployed on workfare $\left(\left.\frac{\partial a}{\partial l_{a}}\right|_{l_{a}=0}>0\right)$, but an overall decrease in the fraction of non-employed $\left(\left.\frac{\partial(u+a)}{\partial l_{a}}\right|_{l_{a}=0}<0\right)$ provided that the incidence of workfare is not too large, i.e. $p_{a u}<\bar{p}_{a u}$. Note that these results indicate that the overall effects of changes in the elements of workfare depend critically on the total policy package, that is, the incidence $\left(p_{a u}\right)$ and the work requirement $\left(l_{a}\right)$.

Finally, it may be questioned whether introduction of workfare policies is tantamount to a two-tier benefit scheme ${ }^{15}$ where there is a transition from a high $(b)$ to a low $\left(b_{L}<b\right)$

\footnotetext{
${ }^{15}$ Albrecht and Vroman (2005) show in a wage posting model how time-varying unemployment benefits
} 
benefit level since this will also induce an incentive effect to search more actively for jobs for those in the first tier. It is relatively straightforward to show that there is no equivalence between a workfare policy and a two-tier benefit scheme ${ }^{16}$. The intuition is that the two schemes will affect utility and search incentives differently.

\section{Numerical illustrations}

To analyse how workfare policies affect labour market performance, we provide in this section numerical illustrations of the main effects of variations in the two dimensions of workfare policies. We report the results by means of simulations of the model. To emphasize the wage effect of workfare, we present the results allowing for a decomposition between the total equilibrium effect (termed the full model) and when the wage is kept fixed. This can be interpreted as a decomposition of the total equilibrium effect into a search and a wage component, cf. the effects of workfare outlined above.

In the spirit of Frederiksson \& Holmlund (2005), we let the instantaneous utility for type $i=e, u, a$ be given by

$$
u_{i}=\ln c_{i}+\ln f_{i}
$$

where $c$ denotes consumption and $f$ denotes leisure. Specifically, the utility functions for the three types of agents amount to:

$$
\begin{aligned}
& u_{e}=\ln d w+\ln \left(1-l_{e}\right) \\
& u_{u}=\ln \lambda w+\ln \left(1-s_{u}\right) \\
& u_{a}=\ln \lambda w+\ln \left(1-s_{a}-l_{a}\right) .
\end{aligned}
$$

can generate wage dispersion in equilibrium. This possibility does not arise in this setting with wages set in a bargaining process.

${ }^{16}$ For this to be the case, the equilibrium attained for a given workfare policy $\left(b, p_{a u}, l_{a}\right)$ should be replicated for a scheme where there is a transition to a lower benefit level $\left(b, p_{a u}, b_{L}\right)$. For this to be the case, there are two conditions, namely that the utility levels should be the same under the two policies, i.e.

$$
g\left(b, 1-s_{a}-l_{a}\right)=g\left(b_{L}, 1-s_{a}\right)
$$

and the search effort should be the same, requiring

$$
v_{F}^{\prime}\left(b, 1-s_{a}-l_{a}\right)=v_{F}^{\prime}\left(b_{L}, 1-s_{a}\right)
$$

Clearly there is in general no level of $b_{L}$ satisfying both conditions. 
where $d>1$ is a non-monetary return to employment. Unemployment insurance benefits are proportional to the wage ${ }^{17}$ and represented by the replacement ratio $\lambda<1$.

Again, following among others Frederiksson \& Holmlund (2001, 2005), the matching function is assumed to be Cobb-Douglas of the form $m=s^{\eta} v^{1-\eta}$, with $\eta=0.5$. Also, in the tradition of the search literature, we impose the Hosios-condition (Hosio, 1990) and set $\beta=\eta=0.5$.

To match the features of the Danish labour market, we set public consumption, $r=0.25$, which corresponds to public expenditure of around $30 \%$ of GDP and the cost of activating unemployed in workfare programmes, $c=0.025$, which corresponds to around $3 \%$ af GDP. Unemployment insurance in Denmark is relatively generous, and to accommodate this, the replacement rate is set to $\lambda=0.6$. We discount utility at $\rho=0.01$ and assume that workers spend $60 \%$ of their time at work, $l_{e}=0.6$. The exogenous exit rate from employment, $p_{u e}=0.07$, is set to fit the unemployment rate at around $8 \%$ in Denmark in the period before increased use of workfare programmes (see e.g. Andersen $\&$ Svarer, 2007). Finally, output is set to $y=1$, vacancy costs are set to $k=1$ and $d=4$.

We have conducted simulations for a wide range of parameter values, and the qualitative results are in most cases not dependent on the particular parameter choices. In the following, it will be pointed out which results are robust to parameter variations and which are sensitive.

\subsection{Intensity of workfare $\left(p_{u a}\right)$}

We start by considering the intensity of workfare, i.e. the probability by which unemployed are required to participate in some activation measure to remain eligible for unemployment benefits. We assume for the moment that the workfare requirement corresponds to full time employment $\left(l_{a}=l_{e}=0.6\right)$. In Figure 1, we show that there is both a locking-in effect, since activated spend less time searching for jobs than unemployed, and a threat effect, since the search activity for the unemployed increases in the workfare intensity. Notice that in accordance with expression (11), the search intensity for the activated is decreasing in workfare intensity due to the lower expected value of getting a job. Search intensity is basically similar across the simulations with fixed and flexible wages, which reflects that the replacement rate is constant. Lower wages and a higher search intensity by the unemployed increase the incentive for employers to create jobs, and the vacancy

\footnotetext{
${ }^{17}$ In Denmark, benefits are indexed to wages.
} 
rate increases. As the search intensities are basically unaffected by the wage drop, the vacancy increase is accordingly mainly driven by the possibility for employers to earn a higher profit per vacancy since the wage cost is reduced (productivity of labour is constant).

Figure 1: Effect of workfare intensity on search, wages and vacancies

Search intensity in activation $\left(\mathbf{s}_{\mathrm{a}}\right)$

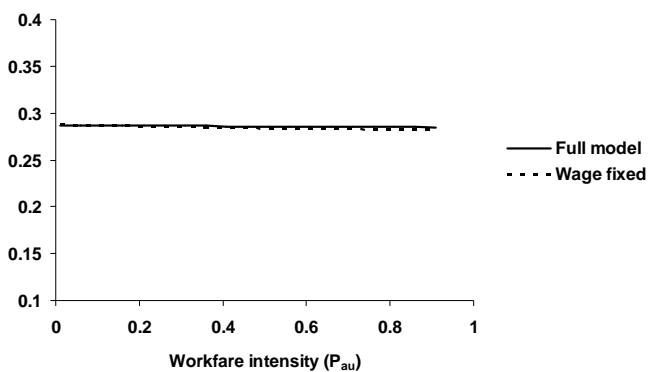

Wages (w)

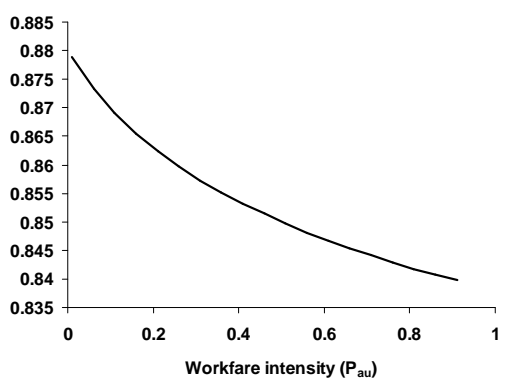

Search intensity for unemployed $\left(\mathbf{s}_{u}\right)$

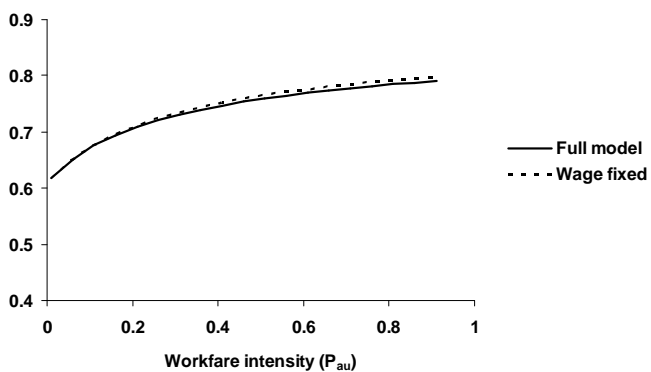

Vacancies (v)
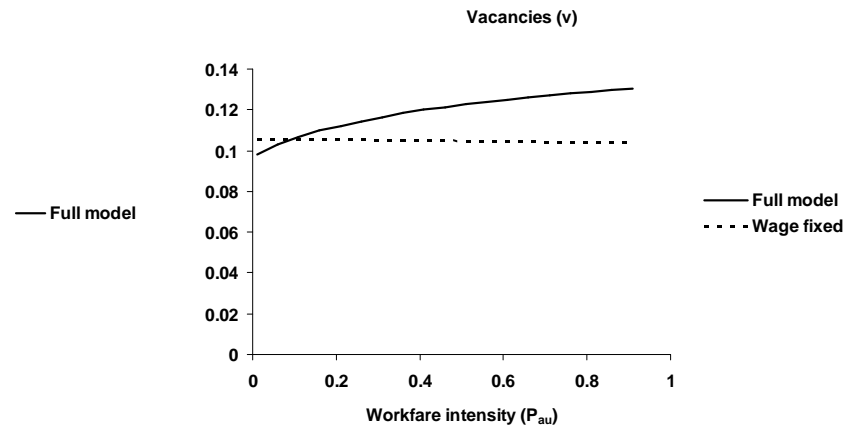

In Figure 2, we see that the increased number of vacancies lowers unemployment and that the drop in unemployment is larger when the wage effect is included. Not surprisingly, the number of activated increases, and in the model without the wage effect, it increases even more. Considering total unemployment, we find that increasing the intensity of workfare from a low level will lower total unemployment, while at a high intensity, a further increase may increase total unemployment marginally. That is, at a low intensity of workfare the threat and wage effects dominate, while at higher levels the locking-in effect dominates. Total search effort decreases for the particular values of the parameters applied. This finding could very well turn around if the workfare requirement was lowered, giving the activated more time to search.

Figure 2: Effect of workfare intensity on labour market status 
Unemployment (u)

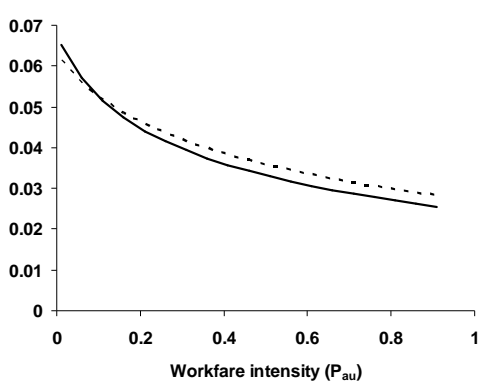

Unemployment+activation $(\mathrm{u}+\mathrm{a})$

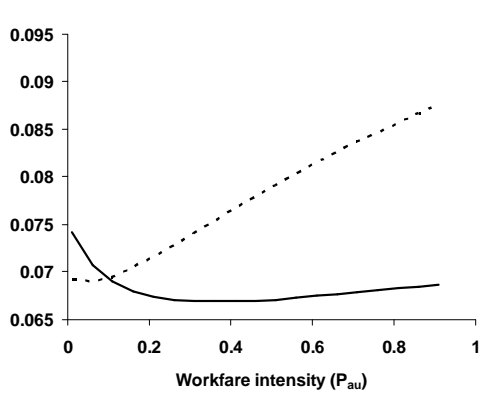

Activated (a)

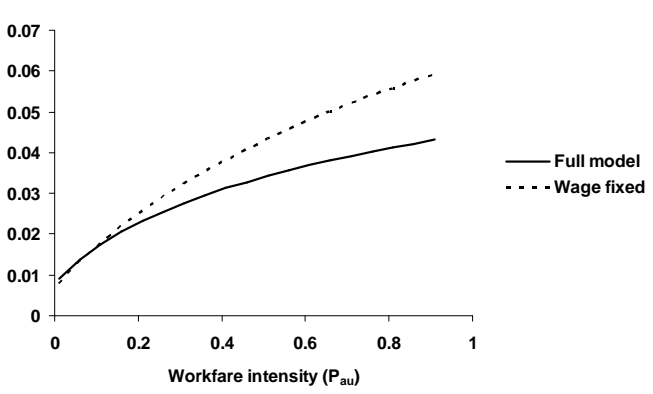

Total search effort $\left(s=u^{*} s_{u}+a^{*} s_{a}\right)$

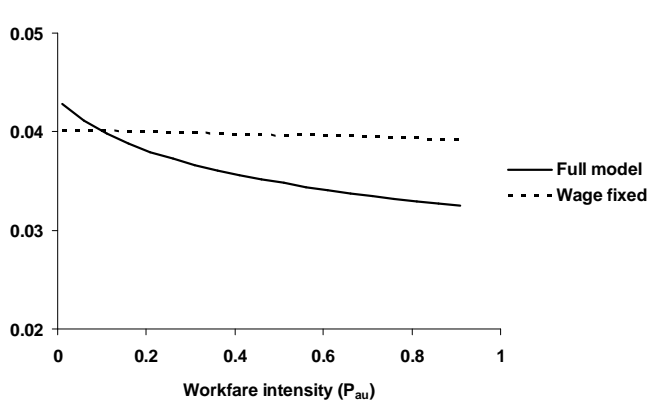

Note that since the wage decreases, it follows that the economic net-gain from finding a job is reduced, and yet unemployment falls. The reason is that workfare makes claiming of benefits less attractive. Considering welfare, we have that the pay-offs in all three labour market states develop similarly; that is, the distributional profile is not much changed, cf. Figure 3.

Figure 3: Pay-offs in labour market states: employment, unemployment and activation

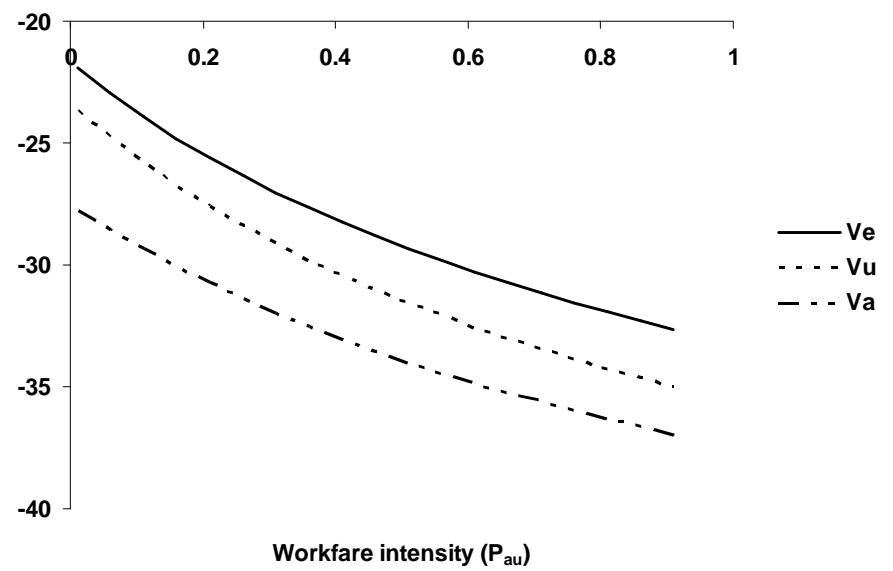


Finally, note that the locking in effect of workfare on the search effort of the activated and the fact that more people are in activation are both poor indicators of the direction in which unemployment (open and total) moves due to workfare policies. This in turn points to the problems in assessing labour market policies from a partial perspective. The same applies when relating total search to unemployment.

\subsection{Work requirements in workfare $\left(l_{a}\right)$}

In this section, the workfare intensity $\left(p_{a u}\right)$ is fixed at 0.46 , and we show how increasing the work requirement affects various labour market outcomes. In Figure 4, it is shown that increasing the workfare requirement lowers search activity for the activated due to the locking-in effect and increases the search intensity for the unemployed due to the threat effect. Whereas the latter effect follows unambiguously from the model presented earlier, the former could, for other parameter values, also be increasing. The deterioration of the outside option of workers causes a reduction in the wage which induces more vacancies.

\section{Figure 4: Effects of workfare requirement on search intensity, wages and} vacancies

Search intensity in activation $\left(\mathbf{s}_{\mathrm{a}}\right)$

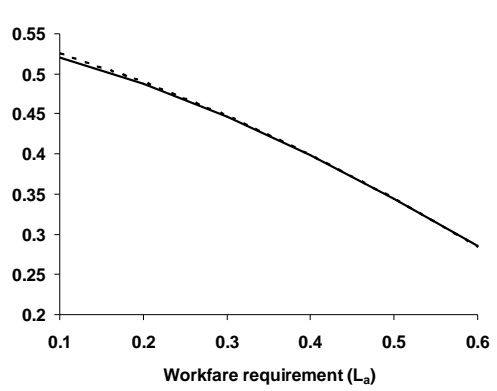

Wages (w)

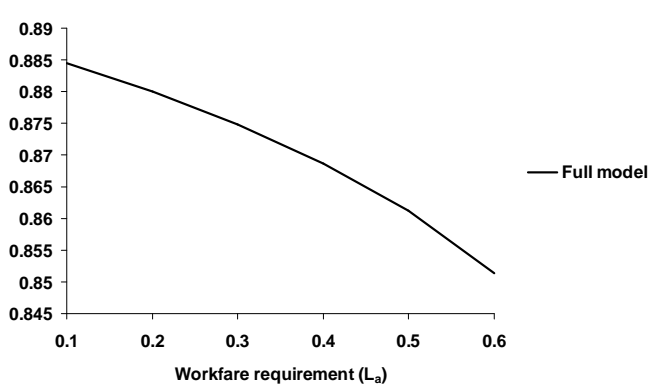

Search intensity for unemployed $\left(\mathbf{s}_{u}\right)$

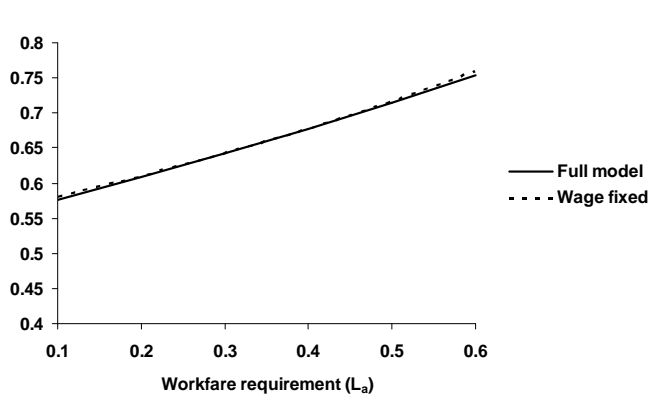

Vacancies (v)

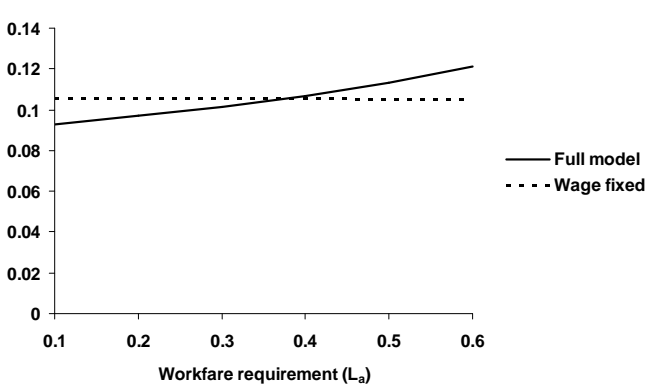


As shown in Figure 5, the increase in vacancies alongside the more intensive search effort by the unemployed lowers open unemployment. For a fixed wage, the number of activated increases due to the locking-in effect. With an endogenous wage, the number in activation follows a U-path in the work requirement. This is the result of the lockingin effect tending to increase the number of activated and the improved return to search due to lower unemployment. Hence, the job-creation effect dominates for a low work requirement, and the locking-in effect dominates for a high work requirement.

Figure 5 also shows that the total search effort is almost constant, reflecting that search increases for unemployed (threat effect) and decreases for the activated (locking-in effect). Vacancies are increasing in the work requirement due to the wage effect. A higher work requirement thus tends to lower unemployment via the threat and wage effects, and to increase it via the locking-in effect (both less search and more in activation). In general, a non-monotone relationship may arise, but for the particular parameter values chosen here, we get that total unemployment is unambiguously decreasing in the work requirement.

\section{Figure 5: Effects of workfare requirement on labour market status}

Unemployment (u)

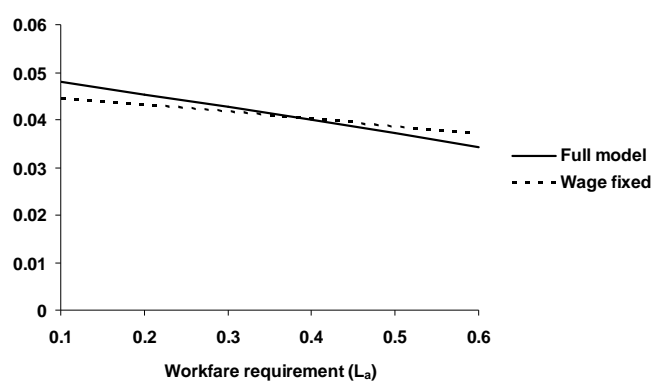

Unemployment+activation $(u+a)$

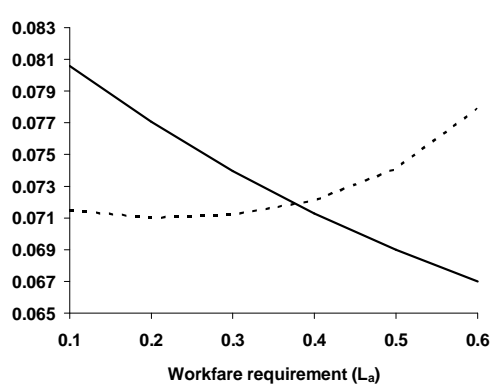

Activated (a)

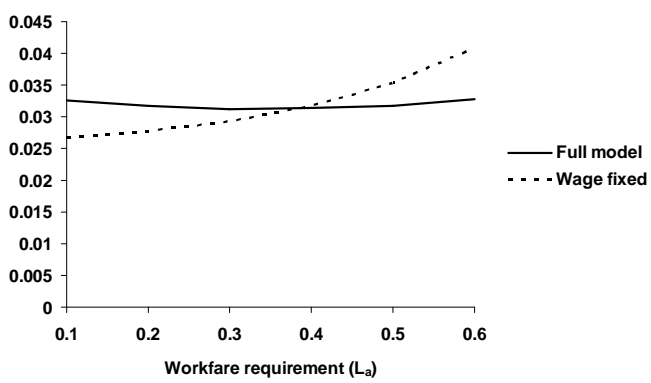

Total search effort $\left(s=\mathbf{u}^{*} \mathbf{s}_{\mathrm{u}}+\mathrm{a}^{*} \mathbf{s}_{\mathrm{a}}\right)$

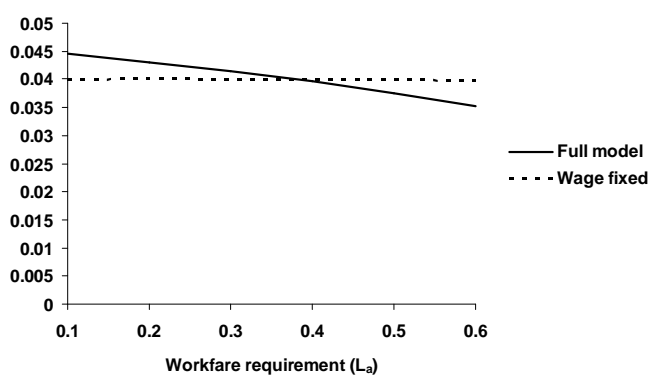

Again, the increasing workfare reduces welfare for agents in all three labour market states. Compared to the situation with intensified workfare, increasing workfare require- 
ment is tougher for those in activation, leading to a non-proportional development in welfare as workfare requirements are strengthened.

Figure 6: Pay-offs in labour market states: employment, unemployment and activation

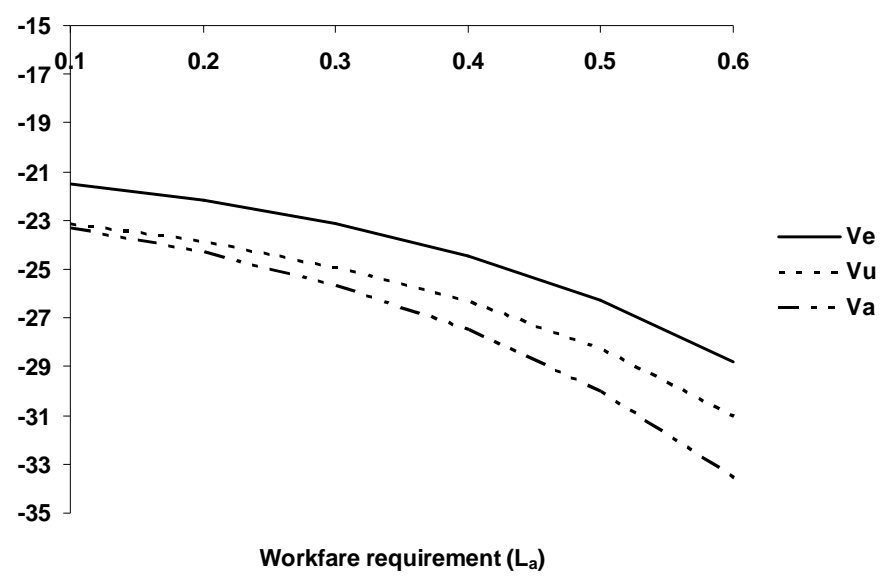

\subsection{Distributional effects}

As indicated above, workfare influences both the expected income and expected utility of agents in the model. To summarize the main effects, Figure 7 shows how mean income and mean utility for workers are affected as workfare is intensified. The mean income profiles are basically flat across both workfare intensity and workfare requirement, suggesting that the effects of the wage decrease are countered by the increase in employment. The expected utility profiles are negatively sloped, suggesting that the transition of individuals from unemployment to employment is not sufficient to counteract the drop in utility that follows from intensified workfare. On the other hand, the negative effect on utility is smaller for the full model, where the vacancy effect implies that fewer people are unemployed. A direct consequence of Figure 7 is that employers benefit from workfare since the profit share is increasing.

Figure 7: Effects of workfare requirement on mean income and mean utility 

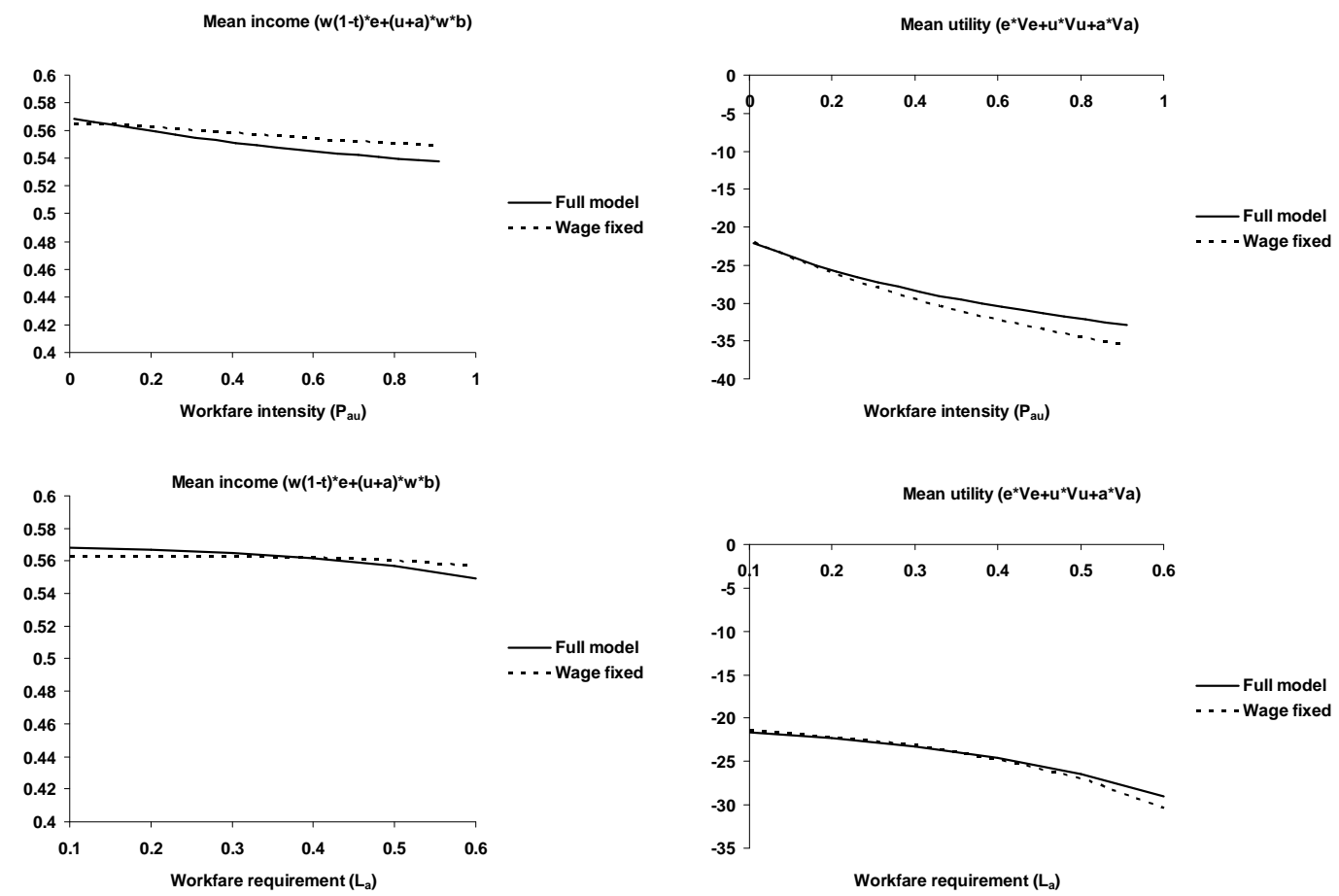

\section{Concluding remarks}

The present equilibrium search model has shown that workfare releases a locking-in, a threat and a wage effect; i.e. it affects the position of all three groups in the labour market (the activated, the unemployed and the employed). Empirical assessments of workfare policies tend to focus on the search effects for those in activation, but the present analysis shows that the wage effect is crucial for the effects.

It was found that a change in workfare - both the intensity and the work requirement - may shift the trade-off between insurance and incentives in the labour market. In the analysis benefits where kept constant $^{18}$, and it was shown that workfare could be used to improve the incentive structure, creating more jobs and lowering (open and total) unemployment. It is also an implication of the analysis that partial results - theoretical and empirical - of the effects of workfare policies may be a poor metric for the overall effects due to the interplay between the three effects of workfare policies.

Taking the simulations presented here at face value implies that policy makers wishing to maximize GDP and hence minimize total unemployment should adopt intermediate levels of workfare intensity but strict workfare requirements. Ignoring the wage effect, the

\footnotetext{
${ }^{18}$ In the numerical analysis, the replacement rate is constant.
} 
suggestion would be to have relatively low intensity and low workfare requirement. It is not surprising that including the wage effects makes workfare more attractive. Whether policies should be more strict in terms of workfare requirement than workfare intensity is hard to generalize. It appears well established empirically that workfare has a strong locking-in effect $\frac{\partial s_{a}}{\partial l_{a}}<0$ (see e.g. Heckman et al. (1999) and Kluve (2006)), and this suggests that caution should be taken in terms of having too high workfare intensity. Increasing workfare requirements can thus be sufficient to generate wage effects, and hence to increase job creation, and potentially to increase the effective job finding rate, leaving room for medium levels of workfare intensity.

An important topic for future research is to analyse the optimal design of workfare policies and to compare it with other dimensions of labour market policies like timedependent benefits, sanctions etc. A question which is complicated since it has to take distributional concerns seriously. In this context, it would be interesting to include different types of workers with different types of unemployment risks since this is an important aspect for policy design. 


\section{References}

\section{References}

[1] Albrecht, J. and S. Vroman, 2005, Equilibrium search with time-varying unemployment benefits, Economic Journal, 115, 631-648.

[2] Andersen, T.M., and M. Svarer, 2007, Flexicurity - Labour market performance in Denmark, CESifo Studies, 53(3), 389-429.

[3] Besley, T., and S. Coate, 1992, Workfare versus welfare: Incentive arguments for work requirements in poverty-alleviation programs, American Economic Review, 82(1), 249-61.

[4] Besley, T., and S. Coate, 1995, The design of income maintenance programmes, Review of Economic Studies, 62, 187-221.

[5] Betts, C., 1998, Who should be on workfare? The use of work requirements as part of an optimal tax mix, Oxford Economic Papers, 50, 607-22.

[6] Chambers, R.G., 1989, Workfare or welfare? Journal of Public Economics, 40, 79-97.

[7] Cuff, K., 2000, Optimality of workfare with heterogenous preferences, Canadian Journal of Economics, 33(1), 149-74.

[8] Frederiksson, P. and B. Holmlund, 2006, Optimal unemployment insurance design: time limits, monitoring, or workfare, International Tax and Public Finance, 13, 565585 .

[9] Heckman, J., R. Lalonde and J. Smith, 1999, The economics and econometrics of ALMP, Handbook of Labor Economics, Vol. 3, North-Holland, Amsterdam.

[10] Holzner, C., V.Meier and M. Werding, 2006, Workfare, monitoring and efficiency wages, CESifo Working Paper 1749.

[11] Kolm, A.-S., and M. Tonin, 2007, In-Work Benefits in Search Equilibrium, Working Paper. 
[12] Kreiner, C.T., and T. Tranæs, 2005, Optimal workfare with voluntary and involuntary unemployment, Scandinavian Journal of Economics.107 (3), 459-474.

[13] Kluve, J., 2006, The Effectiveness of European Active Labour Market Policy, IZA Discussion Paper 2018.

[14] Luttens, R.I. and M.-A. Valfort, 2007, Voting for redistribution under desert-sensitive altruism, Working paper.

[15] Pavoni, N., and G.L.Violante, 2007, Optimal Welfare-to-Work Programs, Review of Economic Studies, 74, 283-318. 


\section{Appendix}

\section{A: Utility gains}

We have from (1), (2) and (3)

$$
\begin{aligned}
\left(\rho+p_{u e}+\alpha s_{u}\right)\left(V^{E}-V^{U}\right) & =h\left(w[1-\tau], 1-l_{e}\right)-g\left(b, 1-s_{u}\right)+p_{a u}\left(V^{U}-V^{A}\right) \\
\left(\rho+\alpha s_{a}\right)\left(V^{E}-V^{A}\right) & =h\left(w[1-\tau], 1-l_{e}\right)-g\left(b, 1-s_{a}-l_{a}\right)+p_{u e}\left(V^{U}-V^{E}\right)
\end{aligned}
$$

which can be written

$$
\begin{aligned}
\left(\rho+p_{u e}+\alpha s_{u}\right)\left(V^{E}-V^{U}\right) & =h\left(w[1-\tau], 1-l_{e}\right)-g\left(b, 1-s_{u}\right)+p_{a u}\left(V^{U}-V^{E}+V^{E}-V^{A}\right) \\
\left(\rho+\alpha s_{a}\right)\left(V^{E}-V^{A}\right) & =h\left(w[1-\tau], 1-l_{e}\right)-g\left(b, 1-s_{a}-l_{a}\right)+p_{u e}\left(V^{U}-V^{E}\right)
\end{aligned}
$$

yielding

$$
\begin{aligned}
\left(\rho+p_{u e}+p_{a u}+\alpha s_{u}\right)\left(V^{E}-V^{U}\right) & =h\left(w[1-\tau], 1-l_{e}\right)-g\left(b, 1-s_{u}\right)+p_{a u}\left(V^{E}-V^{A}\right) \\
\left(\rho+\alpha s_{a}\right)\left(V^{E}-V^{A}\right) & =h\left(w[1-\tau], 1-l_{e}\right)-g\left(b, 1-s_{a}-l_{a}\right)+p_{u e}\left(V^{U}-V^{E}\right)
\end{aligned}
$$

It follows that

$$
\begin{aligned}
\left(V^{E}-V^{U}\right) & =\frac{h\left(w[1-\tau], 1-l_{e}\right)-g\left(b, 1-s_{u}\right)+\frac{p_{a u}\left[u\left(\widetilde{w}, 1-l_{e}\right)-v\left(b, 1-s_{a}-l_{a}\right)\right]}{\rho+\alpha s_{a}}}{\rho+p_{u e}+p_{a u}+\alpha s_{u}+\frac{p_{a u} p_{u e}}{\rho+\alpha s_{a}}} \\
\left(V^{E}-V^{A}\right) & =\frac{h\left(w[1-\tau], 1-l_{e}\right)-g\left(b, 1-s_{a}-l_{a}\right)-\frac{p_{u e}\left[u\left(\widetilde{w}, 1-l_{e}\right)-v\left(b, 1-s_{u}\right)\right]}{\rho+p_{u e}+p_{a u}+\alpha s_{u}}}{\rho+\alpha s_{a}+\frac{p_{u e} p_{a u}}{\rho+p_{u e}+p_{a u}+\alpha s_{u}}}
\end{aligned}
$$

\section{B: Marginal rates of substitution}

Consider combinations of the transition probability $\left(p_{a u}\right)$ and work requirement $\left(l_{a}\right)$ leaving the utility gain of employed relative to unemployed unchanged and the utility gain of those on unemployment benefits relative to those on workfare unchanged, i.e.

$$
\begin{aligned}
& V^{E}-V^{U}=\text { constant } \\
& V^{E}-V^{A}=\text { constant }
\end{aligned}
$$

or

$$
d\left(V^{E}-V^{U}\right)=0=d\left(V^{E}-V^{A}\right)
$$


we have from (18)

$$
\begin{aligned}
& \left(1+\frac{p_{u e}}{\rho+\alpha s_{a}}\right)\left(V^{E}-V^{U}\right) d p_{a u} \\
= & \frac{d p_{a u}}{\rho+\alpha s_{a}}\left[h\left(w[1-\tau], 1-l_{e}\right)-g\left(b, 1-s_{a}-l_{a}\right)\right]+\frac{p_{a u}}{\rho+\alpha s_{a}} v_{F}^{\prime}\left(b, 1-s_{a}-l_{a}\right) d l_{a} \\
& \frac{p_{a u}}{\rho+\alpha s_{a}} g_{F}^{\prime}\left(b, 1-s_{a}-l_{a}\right) d l_{a} \\
= & {\left[\left(1+\frac{p_{u e}}{\rho+\alpha s_{a}}\right)\left(V^{E}-V^{U}\right)-\frac{1}{\rho+\alpha s_{a}}\left[h\left(w[1-\tau], 1-l_{e}\right)-g\left(b, 1-s_{a}-l_{a}\right)\right]\right] d p_{a u} }
\end{aligned}
$$

Using that

$$
\left(\rho+\alpha s_{a}\right)\left(V^{E}-V^{A}\right)-p_{u e}\left(V^{U}-V^{E}\right)=h\left(w[1-\tau], 1-l_{e}\right)-g\left(b, 1-s_{a}-l_{a}\right)
$$

we get

$$
\begin{aligned}
& \frac{p_{a u}}{\rho+\alpha s_{a}} g_{F}^{\prime}\left(b, 1-s_{a}-l_{a}\right) d l_{a} \\
= & {\left[\left(1+\frac{p_{u e}}{\rho+\alpha s_{a}}\right)\left(V^{E}-V^{U}\right)-\frac{1}{\rho+\alpha s_{a}}\left[\left(\rho+\alpha s_{a}\right)\left(V^{E}-V^{A}\right)-p_{u e}\left(V^{U}-V^{E}\right)\right]\right] d p_{a u} } \\
= & {\left[\left(V^{A}-V^{U}\right)\right] d p_{a u} }
\end{aligned}
$$

Hence,

$$
\left.\frac{d p_{a u}}{d l_{a}}\right|_{U}=-\frac{p_{a u}}{\rho+\alpha s_{a}} \frac{g_{F}^{\prime}\left(b, 1-s_{a}-l_{a}\right)}{V^{U}-V^{A}}<0
$$

Similarly, we have from (19)

$$
\begin{aligned}
& {\left[\frac{p_{u e}\left(\rho+p_{u e}+p_{a u}+\alpha s_{u}\right)-p_{u e} p_{a u}}{\left(\rho+p_{u e}+p_{a u}+\alpha s_{u}\right)^{2}}\right]\left(V^{E}-V^{A}\right) d p_{a u} } \\
= & g_{F}^{\prime}\left(b, 1-s_{a}-l_{a}\right) d l_{a}+\frac{p_{u e}}{\left(\rho+p_{u e}+p_{a u}+\alpha s_{u}\right)^{2}}\left[h\left(w[1-\tau], 1-l_{e}\right)-g\left(b, 1-s_{u}\right)\right] d p_{a u} \\
& {\left[\left(\rho+p_{u e}+\alpha s_{u}\right)\left(V^{E}-V^{A}\right)-\left[h\left(w[1-\tau], 1-l_{e}\right)-g\left(b, 1-s_{u}\right)\right]\right] \frac{p_{u e}}{\left(\rho+p_{u e}+p_{a u}+\alpha s_{u}\right)^{2}} d p_{a u} } \\
= & g_{F}^{\prime}\left(b, 1-s_{a}-l_{a}\right) d l_{a}
\end{aligned}
$$

using that

$\left(\rho+p_{u e}+p_{a u}+\alpha s_{u}\right)\left(V^{E}-V^{U}\right)=h\left(w[1-\tau], 1-l_{e}\right)-g\left(b, 1-s_{u}\right)+p_{a u}\left(V^{E}-V^{A}\right)$ 
we get

$$
\begin{aligned}
& {\left[\left(\rho+p_{u e}+\alpha s_{u}+p_{a u}\right)\left(V^{E}-V^{A}\right)-\left(\rho+p_{u e}+p_{a u}+\alpha s_{u}\right)\left(V^{E}-V^{U}\right)\right] \frac{p_{u e}}{\left(\rho+p_{u e}+p_{a u}+\alpha s_{u}\right)^{2}} d p_{a} } \\
= & g_{F}^{\prime}\left(b, 1-s_{a}-l_{a}\right) d l_{a} \\
& \quad-\left(V^{A}-V^{U}\right) \frac{p_{u e}}{\rho+p_{u e}+p_{a u}+\alpha s_{u}} d p_{a u}=g_{F}^{\prime}\left(b, 1-s_{a}-l_{a}\right) d l_{a}
\end{aligned}
$$

Hence,

$$
\left.\frac{d p_{a u}}{d l_{a}}\right|_{A}=\frac{\rho+p_{u e}+p_{a u}+\alpha s_{u}}{p_{u e}} \frac{g_{F}^{\prime}\left(b, 1-s_{a}-l_{a}\right)}{V^{U}-V^{A}}>0
$$

\section{C: Impact effects of changes in workfare policies}

To see the effects of workfare policies, it is useful to consider the impact effects of changes in the two elements of workfare, namely the transition probability $\left(p_{a u}\right)$ and work requirement $\left(l_{a}\right)$ on the utility gains for given macro variables $(w, \alpha, \tau)$. We have

$$
\begin{aligned}
\left(\rho+p_{u e}+p_{a u}+\alpha s_{u}\right)\left(V^{E}-V^{U}\right) & =h\left(w[1-\tau], 1-l_{e}\right)-g\left(b, 1-s_{u}\right)+p_{a u}\left(V^{E}-V^{A}\right) \\
\left(\rho+\alpha s_{a}\right)\left(V^{E}-V^{A}\right) & =h\left(w[1-\tau], 1-l_{e}\right)-g\left(b, 1-s_{a}-l_{a}\right)+p_{u e}\left(V^{U}-V^{E}\right)
\end{aligned}
$$

Hence,

$$
\begin{aligned}
\frac{\partial\left(V^{E}-V^{U}\right)}{\partial l_{a}} & =\frac{p_{a u}}{\rho+p_{u e}+p_{a u}+\alpha s_{u}} \frac{\partial\left(V^{E}-V^{A}\right)}{\partial l_{a}} \\
\frac{\partial\left(V^{E}-V^{A}\right)}{\partial l_{a}} & =\frac{1}{\rho+\alpha s_{a}} g_{F}^{\prime}\left(b, 1-s_{a}-l_{a}\right)-\frac{p_{u e}}{\rho+\alpha s_{a}} \frac{\partial\left(V^{E}-V^{U}\right)}{\partial l_{a}} \\
\frac{\partial\left(V^{E}-V^{U}\right)}{\partial p_{a u}} & =\frac{1}{\rho+p_{u e}+p_{a u}+\alpha s_{u}}\left[\left(V^{U}-V^{A}\right)+p_{a u} \frac{\partial\left(V^{E}-V^{A}\right)}{\partial p_{a u}}\right] \\
\frac{\partial\left(V^{E}-V^{A}\right)}{\partial p_{a u}} & =-\frac{p_{u e}}{\rho+\alpha s_{a}} \frac{\partial\left(V^{E}-V^{U}\right)}{\partial p_{a u}}
\end{aligned}
$$

Hence, we have

$$
\begin{array}{ll}
\frac{\partial\left(V^{E}-V^{U}\right)}{\partial l_{a}}>0 & \frac{\partial\left(V^{E}-V^{U}\right)}{\partial p_{a u}}>0 \\
\frac{\partial\left(V^{E}-V^{A}\right)}{\partial l_{a}}>0 & \frac{\partial\left(V^{E}-V^{A}\right)}{\partial p_{a u}}<0
\end{array}
$$

\section{D: Equilibrium}

The model can be summarized by the following 10 equations in the following endogenous variables: $V^{E}-V^{U}, V^{E}-V^{A}, s_{a}, s_{u}, a, u, w, q, \alpha, \theta$. 
Pay-off gains:

$$
\begin{aligned}
V^{E}-V^{U} & =\frac{h\left(w[1-\tau], 1-l_{e}\right)-g\left(b, 1-s_{u}\right)+p_{a u}\left(V^{U}-V^{A}\right)}{\rho+p_{u e}+\alpha s_{u}} \\
V^{E}-V^{A} & =\frac{h\left(w[1-\tau], 1-l_{e}\right)-g\left(b, 1-s_{a}-l_{a}\right)+p_{u e}\left(V^{U}-V^{E}\right)}{\rho+\alpha s_{a}}
\end{aligned}
$$

Search effort:

$$
\begin{aligned}
g_{F}^{\prime}\left(b, 1-s_{u}\right) & =\alpha\left[V^{E}-V^{U}\right] \\
g_{F}^{\prime}\left(b, 1-s_{a}-l_{a}\right) & =\alpha\left[V^{E}-V^{A}\right]
\end{aligned}
$$

Inflow and outflows:

$$
\begin{aligned}
{[1-u-a] p_{u e} } & =\alpha(\theta)\left[s_{u} u+s_{a} a\right] \\
\alpha(\theta) s_{a} a & =p_{a u} u
\end{aligned}
$$

Job creation and wage setting:

$$
\begin{aligned}
w & =\left[1-\left(\rho+p_{u e}\right) \frac{k}{q}\right] y \\
0 & =\beta \frac{u_{w}\left(w(1-\tau), 1-l_{e}\right)}{V^{E}-V^{U}}-(1-\beta) \frac{q}{k y}
\end{aligned}
$$

Job-finding and job-filling rates:

$$
\begin{aligned}
\alpha & =\frac{m(s, v)}{s}=m(1, \theta), m_{\theta}>0 \\
q & =\frac{m(s, v)}{v}=m\left(\theta^{-1}, 1\right), q^{\prime}(\theta)<0 ; \theta=\frac{v}{s}
\end{aligned}
$$

Using (26), (28) and (29), we have

$$
\begin{aligned}
q=\widetilde{q}(w) & \frac{\partial \widetilde{q}(w)}{\partial w}>0 \\
\alpha=\widetilde{\alpha}(w) & \frac{\partial \widetilde{\alpha}(w)}{\partial w}<0 \\
\theta=\widetilde{\alpha}(w) & \frac{\partial \widetilde{\theta}(w)}{\partial w}<0
\end{aligned}
$$

Search activities can from (22) and (22) be written

$$
\begin{aligned}
& s_{u}=\Phi\left(\widetilde{\alpha}(w)\left[V^{E}-V^{U}\right]\right) \\
& s_{a}=\Phi\left(\widetilde{\alpha}(w)\left[V^{E}-V^{A}\right]\right)-l_{a}
\end{aligned}
$$


and using this in (20) and (21), it follows that utility gains can be written

$$
\begin{aligned}
V^{E}-V^{U} & =F\left(w, \tau, \widetilde{\alpha}(w), p_{a u}, l_{a}\right) \\
V^{E}-V^{A} & =G\left(w, \tau, \widetilde{\alpha}(w), p_{a u}, l_{a}\right)
\end{aligned}
$$

Finally, the wage equation (26) can now be written

$$
\beta \frac{u_{w}\left(w(1-\tau), 1-l_{e}\right)}{V^{E}-V^{U}}-(1-\beta) \frac{q(\theta)}{k y}=0
$$

or $^{19}$

$$
\begin{aligned}
0 & =\Psi\left(w, \tau, \widetilde{q}(w), V^{E}-V^{U}\right) \quad \Psi_{w}<0, \Psi_{V^{E}-V^{U}}<0 \\
& =\Psi\left(w, \tau, \widetilde{q}(w), F\left(w, \tau, \widetilde{\alpha}(w), p_{a u}, l_{a}\right)\right)
\end{aligned}
$$

For a given tax rate $\tau$, the equilibrium wage is found as the solution to (30. If the function $\Psi$ is monotonously decreasing in the wage rate, it follows that the equilibrium is unique. This implies that $\frac{\partial w}{\partial p_{a u}}<0, \frac{\partial w}{\partial l_{a}}<0$. Note that an equilibrium where $0<u+a<1$ is ensured since if $u+a=0$, we have $u=a=0$, implying that $\widetilde{\alpha}(w)=p_{u e}$ which is inconsistent with (29), and for $u+a=1$, we have $\widetilde{\alpha}(w)=0$ which is also inconsistent with (29).

Note that endogenizing the tax rate would introduce a non-linearity in the model which potentially could imply multiple equilibria since

$$
\tau=\frac{b u+(b+c) a+r}{w(1-u-a)}
$$

For this reason, the tax rate is assumed constant in the theoretical analysis, but the tax rate is endogenized in the numerical examples.

\section{E: Effects of changes in workfare policies}

In this appendix, we consider how changes in workfare policies $\left(p_{a u}, l_{a}\right)$ affect unemployment $(u)$, activation $(a)$ and total unemployment $(u+a)$.

We have from (12) and (13) that

$$
\begin{aligned}
{[1-u-a] p_{u e} } & =\alpha\left[s_{u} u+s_{a} a\right] \\
\alpha s_{a} a & =p_{a u} u
\end{aligned}
$$

\footnotetext{
${ }^{19}$ Where $\Psi_{w}$ follows from the second order condition.
} 
Hence,

$$
\begin{aligned}
0 & =\left(p_{u e}+\alpha s_{u}\right) \frac{\partial u}{\partial z}+\left(p_{u e}+\alpha s_{a}\right) \frac{\partial a}{\partial z}+u \frac{\partial \alpha s_{u}}{\partial z}+a \frac{\partial \alpha s_{a}}{\partial z} \\
\alpha s_{a} \frac{\partial a}{\partial z}+a \frac{\partial \alpha s_{a}}{\partial z} & =p_{a u} \frac{\partial u}{\partial z}+u \frac{\partial p_{a u}}{\partial z}
\end{aligned}
$$

and it follows that

$$
\begin{aligned}
0 & =\left(p_{u e}+\alpha s_{u}\right) \frac{\partial u}{\partial z}+\frac{p_{u e}+\alpha s_{a}}{\alpha s_{a}}\left[p_{a u} \frac{\partial u}{\partial z}+u \frac{\partial p_{a u}}{\partial z}-a \frac{\partial \alpha s_{a}}{\partial z}\right]+u \frac{\partial \alpha s_{u}}{\partial z}+a \frac{\partial \alpha s_{a}}{\partial z} \\
\frac{\partial u}{\partial z} & =\frac{-\frac{p_{u e}+\alpha s_{a}}{\alpha s_{a}} u \frac{\partial p_{a u}}{\partial z}-u \frac{\partial \alpha s_{u}}{\partial z}+a \frac{p_{u e}}{\alpha s_{a}} \frac{\partial \alpha s_{a}}{\partial z}}{\left(p_{u e}+\alpha s_{u}\right)+\frac{p_{u e}+\alpha s_{a}}{\alpha s_{a}} p_{a u}}
\end{aligned}
$$

Considering the effect on activation, we have

$$
\begin{aligned}
\frac{\partial a}{\partial z} & =\frac{1}{\alpha s_{a}}\left[p_{a u} \frac{\partial u}{\partial z}+u \frac{\partial p_{a u}}{\partial z}-a \frac{\partial \alpha s_{a}}{\partial z}\right] \\
& =\frac{1}{\alpha s_{a}}\left[\frac{p_{a u}\left[-\frac{p_{u e}+\alpha s_{a}}{\alpha s_{a}} u \frac{\partial p_{a u}}{\partial z}-u \frac{\partial \alpha s_{u}}{\partial z}+a \frac{p_{u e}}{\alpha s_{a}} \frac{\partial \alpha s_{a}}{\partial z}\right]+\left[\left(p_{u e}+\alpha s_{u}\right)+\frac{p_{u e}+\alpha s_{a}}{\alpha s_{a}} p_{a u}\right]\left[u \frac{\partial p_{a u}}{\partial z}-a \frac{\partial \alpha s_{a}}{\partial z}\right]}{\left(p_{u e}+\alpha s_{u}\right)+\frac{p_{u e}+\alpha s_{a}}{\alpha s_{a}} p_{a u}}\right] \\
& =\frac{1}{\alpha s_{a}}\left[\frac{\left(p_{u e}+\alpha s_{u}\right) u \frac{\partial p_{a u}}{\partial z}-u p_{a u} \frac{\partial \alpha s_{u}}{\partial z}-\left[p_{u e}+\alpha s_{u}+p_{a u}\right] a \frac{\partial \alpha s_{a}}{\partial z}}{\left(p_{u e}+\alpha s_{u}\right)+\frac{p_{u e}+\alpha s_{a}}{\alpha s_{a}} p_{a u}}\right]
\end{aligned}
$$

and combining the two, the effect on total unemployment is found to be

$$
\frac{\partial u}{\partial z}+\frac{\partial a}{\partial z}=\frac{\left[\frac{\alpha\left(s_{u}-s_{a}\right)}{\alpha s_{a}}\right] u \frac{\partial p_{a u}}{\partial z}-\left[1+\frac{p_{a u}}{\alpha s_{a}}\right] u \frac{\partial \alpha s_{u}}{\partial z}-\left[\frac{\alpha s_{u}+p_{a u}}{\alpha s_{a}}\right] a \frac{\partial \alpha s_{a}}{\partial z}}{\left(p_{u e}+\alpha s_{u}\right)+\frac{p_{u e}+\alpha s_{a}}{\alpha s_{a}} p_{a u}}
$$

In the following, we consider the incremental introduction of workfare policies into a benefit scheme without workfare. We neutralize the unambiguous wage effect and focus on the search effects which in general are ambiguous to show that they are unambiguous for an incremental introduction of workfare. The question addressed is thus whether a marginal introduction of workfare will lower unemployment (both open and total, i.e. $u$ and $u+a$ ) if starting with a benefit scheme without workfare elements. This can happen in one of two ways, either having an initial situation where $\left(p_{a u} . l_{a}\right)=\left(0, l_{a}\right)$ and then rising $p_{a u}$ marginally, or having an initiation situation $\left(p_{a u}, l_{a}\right)=\left(p_{a u}, 0\right)$ and then rising $l_{a}$ marginally. The wage rate $w$ and thus the job finding rate $\alpha$ are constant to focus on the search effect.

(I) Incidence of workfare 
Note that for $p_{a u}=0$, we have $a=0$, and hence

$$
\begin{aligned}
\left.\alpha s_{a} \frac{\partial a}{\partial p_{a u}}\right|_{p_{a u}=0} & =u \\
\left.\left(p_{u e}+\alpha s_{u}\right) \frac{\partial u}{\partial p_{a u}}\right|_{p_{a u}=0} & =-\left.\left(p_{u e}+\alpha s_{a}\right) \frac{\partial a}{\partial p_{a u}}\right|_{p_{a u}=0}+\left.u \alpha \frac{\partial s_{u}}{\partial p_{a u}}\right|_{p_{a u}=0}
\end{aligned}
$$

Implying

$$
\left.\frac{\partial u}{\partial p_{a u}}\right|_{p_{a u}=0}=-\frac{\left(p_{u e}+\alpha s_{a}\right) \frac{u}{\alpha s_{a}}+\left.u \alpha \frac{\partial s_{u}}{\partial p_{a u}}\right|_{p_{a u}=0}}{\left(p_{u e}+\alpha s_{u}\right)}<0
$$

where $\left.\frac{\partial s_{u}}{\partial p_{a u}}\right|_{p_{a u}=0}>0$ follows from (10).

$$
\left.\frac{\partial(u+a)}{\partial p_{a u}}\right|_{p_{a u}=0}=-\frac{\left.u \alpha \frac{\partial s_{u}}{\partial p_{a u}}\right|_{p_{a u}=0}}{\left(p_{u e}+\alpha s_{u}\right)}+\left[1-\frac{\left(p_{u e}+\alpha s_{a}\right)}{\left(p_{u e}+\alpha s_{u}\right)}\right] \frac{u}{\alpha s_{a}}
$$

Note that this is negative for $l_{a}=0$, hence, there exists a $\bar{l}_{a}$ such that $\left.\frac{\partial(u+a)}{\partial p_{a u}}\right|_{p_{a u}=0}<0$.

(II) work requirement

Note that if $l_{a}=0$, agents are similarly situated as unemployed and in activation $\left(s_{a}=s_{u}\right)$, and we have

$$
\begin{aligned}
0 & =\left(p_{u e}+\alpha s_{u}\right)\left[\frac{\partial u}{\partial l_{a}}+\frac{\partial a}{\partial l_{a}}\right]+u \alpha \frac{\partial s_{u}}{\partial l_{a}}+a \alpha \frac{\partial s_{a}}{\partial l_{a}} \\
\alpha s_{a} \frac{\partial a}{\partial l_{a}}+a \alpha \frac{\partial s_{a}}{\partial l_{a}} & =p_{a u} \frac{\partial u}{\partial l_{a}}
\end{aligned}
$$

hence

$$
0=\left(p_{u e}+\alpha s_{u}\right) \frac{\partial u}{\partial l_{a}}+\frac{\left(p_{u e}+\alpha s_{u}\right)}{\alpha s_{a}}\left[p_{a u} \frac{\partial u}{\partial l_{a}}-a \alpha \frac{\partial s_{a}}{\partial l_{a}}\right]+u \alpha \frac{\partial s_{u}}{\partial l_{a}}+a \alpha \frac{\partial s_{a}}{\partial l_{a}}
$$

or

$$
\left[\left(p_{u e}+\alpha s_{u}\right)+\frac{\left(p_{u e}+\alpha s_{u}\right)}{\alpha s_{a}} p_{a u}\right] \frac{\partial u}{\partial l_{a}}=\left[\frac{\left(p_{u e}+\alpha s_{u}\right)}{\alpha s_{a}}-1\right] a \alpha \frac{\partial s_{a}}{\partial l_{a}}-u \alpha \frac{\partial s_{u}}{\partial l_{a}}
$$

We have $\frac{\left(p_{u e}+\alpha s_{u}\right)}{\alpha s_{a}}-1>0$, and hence $\frac{\partial u}{\partial l_{a}}<0$ has as a sufficient condition $\alpha \frac{\partial s_{a}}{\partial l_{a}}<0$. Note that (8) implies that $\alpha \frac{\partial s_{a}}{\partial l_{a}}<0$. For $p_{a u}=0$, we have $a=0$, and $\frac{\partial u}{\partial l_{a}}<0$ and $\frac{\partial u}{\partial l_{a}}+\frac{\partial a}{\partial l_{a}}<0$. Moreover, there is a $\bar{p}_{a u}$ such that for $p_{a u}<\bar{p}_{a u}$, we have $\frac{\partial u}{\partial l_{a}}<0$ and $\frac{\partial u}{\partial l_{a}}+\frac{\partial a}{\partial l_{a}}<0$. 


\section{CESifo Working Paper Series}

for full list see www.cesifo-group.org/wp

(address: Poschingerstr. 5, 81679 Munich, Germany, office@cesifo.de)

2200 Andreas Bühn and Friedrich Schneider, MIMIC Models, Cointegration and Error Correction: An Application to the French Shadow Economy, January 2008

2201 Seppo Kari, Hanna Karikallio and Jukka Pirttilä, Anticipating Tax Change: Evidence from the Finnish Corporate Income Tax Reform of 2005, January 2008

2202 Walter Krämer and André Güttler, On Comparing the Accuracy of Default Predictions in the Rating Industry, January 2008

2203 Syed M. Ahsan and Panagiotis Tsigaris, The Efficiency Loss of Capital Income Taxation under Imperfect Loss Offset Provisions, January 2008

2204 P. Mohnen, F. C. Palm, S. Schim van der Loeff and A. Tiwari, Financial Constraints and other Obstacles: Are they a Threat to Innovation Activity?, January 2008

2205 Sascha O. Becker and Mathias Hoffmann, Equity Fund Ownership and the CrossRegional Diversification of Household Risk, January 2008

2206 Pedro R. D. Bom and Jenny E. Ligthart, How Productive is Public Capital? A MetaAnalysis, January 2008

2207 Martin Werding, Ageing and Productivity Growth: Are there Macro-level Cohort Effects of Human Capital?, January 2008

2208 Frederick van der Ploeg and Steven Poelhekke, Globalization and the Rise of MegaCities in the Developing World, February 2008

2209 Sara Biancini, Regulating National Firms in a Common Market, February 2008

2210 Jin Cao and Gerhard Illing, Liquidity Shortages and Monetary Policy, February 2008

2211 Mathias Kifmann, The Design of Pension Pay Out Options when the Health Status during Retirement is Uncertain, February 2008

2212 Laszlo Goerke, Tax Overpayments, Tax Evasion, and Book-Tax Differences, February 2008

2213 Jun-ichi Itaya and Heinrich W. Ursprung, Price and Death, February 2008

2214 Valentina Bosetti, Carlo Carraro and Emanuele Massetti, Banking Permits: Economic Efficiency and Distributional Effects, February 2008

2215 Assar Lindbeck, Mårten Palme and Mats Persson, Social Interaction and Sickness Absence, February 2008 
2216 Gary E. Bolton and Axel Ockenfels, The Limits of Trust in Economic Transactions Investigations of Perfect Reputation Systems, February 2008

2217 Hartmut Egger and Peter Egger, The Trade and Welfare Effects of Mergers in Space, February 2008

2218 Dorothee Crayen and Joerg Baten, Global Trends in Numeracy 1820-1949 and its Implications for Long-Run Growth, February 2008

2219 Stephane Dees, M. Hashem Pesaran, L. Vanessa Smith and Ron P. Smith, Identification of New Keynesian Phillips Curves from a Global Perspective, February 2008

2220 Jerome L. Stein, A Tale of Two Debt Crises: A Stochastic Optimal Control Analysis, February 2008

2221 Michael Melvin, Lukas Menkhoff and Maik Schmeling, Automating Exchange Rate Target Zones: Intervention via an Electronic Limit Order Book, February 2008

2222 Raymond Riezman and Ping Wang, Preference Bias and Outsourcing to Market: A Steady-State Analysis, February 2008

2223 Lars-Erik Borge and Jørn Rattsø, Young and Old Competing for Public Welfare Services, February 2008

2224 Jose Apesteguia, Steffen Huck, Jörg Oechssler and Simon Weidenholzer, Imitation and the Evolution of Walrasian Behavior: Theoretically Fragile but Behaviorally Robust, February 2008

2225 Walter Krämer, Long Memory with Markov-Switching GARCH, February 2008

2226 António Afonso and Christophe Rault, What do we really Know about Fiscal Sustainability in the EU? A Panel Data Diagnostic, February 2008

2227 Sergey M. Kadochnikov and Igor M. Drapkin, Market Structure, Technological Gap and Vertical Linkage Effects from Foreign Direct Investment, February 2008

2228 Guglielmo Maria Caporale, Davide Ciferri and Alessandro Girardi, Fiscal Shocks and Real Exchange Rate Dynamics: Some Evidence for Latin America, February 2008

2229 Scott Alan Carson, Geography and Insolation in $19^{\text {th }}$ Century US African-American and White Statures, February 2008

2230 Wolfgang Buchholz and Jan Schumacher, Discounting and Welfare Analysis Over Time: Choosing the $\eta$, February 2008

2231 M. Hashem Pesaran, Christoph Schleicher and Paolo Zaffaroni, Model Averaging in Risk Management with an Application to Futures Markets, February 2008

2232 Wilhelm Kohler, Offshoring: Why Do Stories Differ?, February 2008 
2233 Stefan Bach, Giacomo Corneo and Viktor Steiner, Effective Taxation of Top Incomes in Germany, 1992-2002, February 2008

2234 Robert S. Chirinko, $\sigma:$ The Long And Short Of It, February 2008

2235 Volker Grossmann and Holger Strulik, Should Continued Family Firms Face Lower Taxes than other Estates?, February 2008

2236 Guido Tabellini, The Scope of Cooperation: Values and Incentives, February 2008

2237 Heinrich W. Ursprung and Christian Wiermann, Reputation, Price, and Death: An Empirical Analysis of Art Price Formation, March 2008

2238 Hans Fehr and Christian Habermann, Private Retirement Savings in Germany: The Structure of Tax Incentives and Annuitization, March 2008

2239 Joseph Francois and Ian Wooton, Market Structure and Market Access, March 2008

2240 Hiroyuki Kasahara and Beverly Lapham, Productivity and the Decision to Import and Export: Theory and Evidence, March 2008

2241 Gary E. Bolton and Axel Ockenfels, Does Laboratory Trading Mirror Behavior in Real World Markets? Fair Bargaining and Competitive Bidding on EBay, March 2008

2242 Atsushi Oshima, B. Ravikumar and Raymond Riezman, Entrepreneurship, Organization Capital and the Evolution of the Firm, March 2008

2243 Walter Krämer and Sebastian Schich, Large-Scale Disasters and the Insurance Industry, March 2008

2244 Leif Danziger, Adjustment Costs, Inventories and Output, March 2008

2245 Anne van Aaken, Lars P. Feld and Stefan Voigt, Power over Prosecutors Corrupts Politicians: Cross Country Evidence Using a New Indicator, March 2008

2246 Hans-Christian Heinemeyer, Max-Stephan Schulze and Nikolaus Wolf, Endogenous Borders? The Effects of New Borders on Trade in Central Europe 1885-1933, March 2008

2247 Johannes Becker and Clemens Fuest, Tax Competition - Greenfield Investment versus Mergers and Acquisitions, March 2008

2248 Giorgio Bellettini and Hubert Kempf, Why not in your Backyard? On the Location and Size of a Public Facility, March 2008

2249 Jose Luis Evia, Roberto Laserna and Stergios Skaperdas, Socio-Political Conflict and Economic Performance in Bolivia, March 2008

2250 Bas Jacobs and A. Lans Bovenberg, Optimal Taxation of Human Capital and the Earnings Function, March 2008 
2251 Jan-Egbert Sturm and Timo Wollmershäuser, The Stress of Having a Single Monetary Policy in Europe, March 2008

2252 Guido Schwerdt, Labor Turnover before Plant Closure: 'Leaving the Sinking Ship' vs. 'Captain Throwing Ballast Overboard', March 2008

2253 Keith E. Maskus and Shuichiro Nishioka, Development-Related Biases in Factor Productivities and the HOV Model of Trade, March 2008

2254 Jeremy Edwards and Sheilagh Ogilvie, Contract Enforcement, Institutions and Social Capital: the Maghribi Traders Reappraised, March 2008

2255 Imed Drine and Christophe Rault, Purchasing Power Parity for Developing and Developed Countries. What can we Learn from Non-Stationary Panel Data Models?, March 2008

2256 Scott Alan Carson, Health, Wealth and Inequality: a Contribution to the Debate about the Relationship between Inequality and Health, March 2008

2257 C.A.E. Goodhart, The Regulatory Response to the Financial Crisis, March 2008

2258 Stefan Bauernschuster, Oliver Falck and Stephan Heblich, The Impact of Continuous Training on a Firm's Innovations, March 2008

2259 Michael Grimm and Stephan Klasen, Geography vs. Institutions at the Village Level, March 2008

2260 Fwu-Ranq Chang, Property Insurance, Portfolio Selection and their Interdependence, March 2008

2261 J. Atsu Amegashie and Marco Runkel, The Paradoxes of Revenge in Conflicts, March 2008

2262 Hans Jarle Kind, Marko Koethenbuerger and Guttorm Schjelderup, Efficiency Enhancing Taxation in Two-sided Markets, March 2008

2263 M. Hashem Pesaran, Til Schuermann and L. Vanessa Smith, Forecasting Economic and Financial Variables with Global VARs, March 2008

2264 Volker Grossmann, Entrepreneurial Innovation and Sustained Long-run Growth without Weak or Strong Scale Effects, March 2008

2265 Robert S. Chirinko and Huntley Schaller, The Irreversibility Premium, March 2008

2266 Andrea Galeotti and José Luis Moraga-González, Platform Intermediation in a Market for Differentiated Products, April 2008

2267 Torben M. Andersen and Michael Svarer, The Role of Workfare in Striking a Balance between Incentives and Insurance in the Labour Market, April 2008 